\title{
Solvent recycle with imperfect membranes: A semi- continuous workaround for diafiltration
}

DOI:

10.1016/j.memsci.2016.04.056

\section{Document Version}

Accepted author manuscript

Link to publication record in Manchester Research Explorer

\section{Citation for published version (APA):}

Schaepertoens, M., Didaskalou, C., Kim, J., Livingston, A., \& Szekely, G. (2016). Solvent recycle with imperfect membranes: A semi-continuous workaround for diafiltration. Journal of Membrane Science, 514, 646-658. https://doi.org/10.1016/j.memsci.2016.04.056

\section{Published in:}

Journal of Membrane Science

\section{Citing this paper}

Please note that where the full-text provided on Manchester Research Explorer is the Author Accepted Manuscript or Proof version this may differ from the final Published version. If citing, it is advised that you check and use the publisher's definitive version.

\section{General rights}

Copyright and moral rights for the publications made accessible in the Research Explorer are retained by the authors and/or other copyright owners and it is a condition of accessing publications that users recognise and abide by the legal requirements associated with these rights.

\section{Takedown policy}

If you believe that this document breaches copyright please refer to the University of Manchester's Takedown Procedures [http://man.ac.uk/04Y6Bo] or contact uml.scholarlycommunications@manchester.ac.uk providing relevant details, so we can investigate your claim.

\section{OPEN ACCESS}




\section{Author's Accepted Manuscript}

Solvent recycle with imperfect membranes: A semicontinuous workaround for diafiltration

Marc Schaepertoens, Christos Didaskalou, Jeong F. Kim, Andrew G. Livingston, Gyorgy Szekely

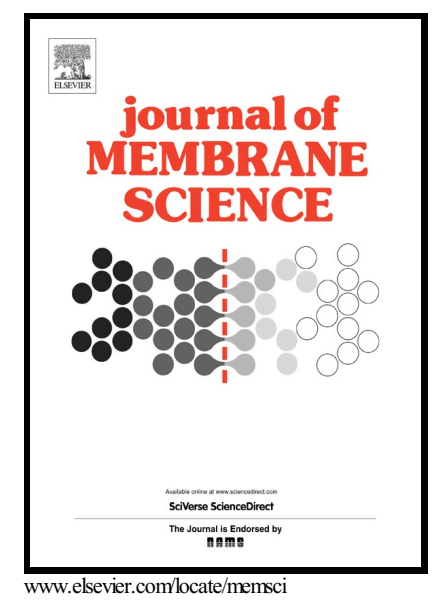

PII: $\quad$ S0376-7388(16)30294-0

DOI: $\quad$ http://dx.doi.org/10.1016/j.memsci.2016.04.056

Reference: MEMSCI14456

To appear in: Journal of Membrane Science

Received date: 8 December 2015

Revised date: 18 April 2016

Accepted date: 23 April 2016

Cite this article as: Marc Schaepertoens, Christos Didaskalou, Jeong F. Kim Andrew G. Livingston and Gyorgy Szekely, Solvent recycle with imperfec membranes: A semi-continuous workaround for diafiltration, Journal c Membrane Science, http://dx.doi.org/10.1016/j.memsci.2016.04.056

This is a PDF file of an unedited manuscript that has been accepted fo publication. As a service to our customers we are providing this early version o the manuscript. The manuscript will undergo copyediting, typesetting, an review of the resulting galley proof before it is published in its final citable form Please note that during the production process errors may be discovered whic could affect the content, and all legal disclaimers that apply to the journal pertain 
Solvent recycle with imperfect membranes: A semi-continuous workaround for diafiltration

Marc Schaepertoens ${ }^{1}$, Christos Didaskalou ${ }^{2}$, Jeong F. Kim ${ }^{1}$, Andrew G. Livingston ${ }^{1}$, Gyorgy Szekely ${ }^{2}$

${ }^{1}$ Department of Chemical Engineering, Imperial College London, South Kensington Campus, London, SW7 2AZ, United Kingdom

${ }^{2}$ School of Chemical Engineering \& Analytical Science, The University of Manchester, The Mill, Sackville Street, Manchester M13 9PL, United Kingdom

* Corresponding authors: +44 (0)20 7594 5582, a.livingston@imperial.ac.uk +44 (0)161306 4366, gyorgy.szekely@ manchester.ac.uk

Keywords: solvent recovery; membrane cascade; organic solvent nanofiltration; solvent consumption; sustainability 


\section{Abstract}

For separation of a two-component mixture, a three-stage organic solvent nanofiltration (OSN) process is presented which comprises of a two-stage membrane cascade for separation with a third membrane stage added for integrated solvent recovery, i.e. solvent recycling. The two-stage cascade allows for increased separation selectivity whilst the integrated solvent recovery stage mitigates the otherwise large solvent consumption of the purification. This work explores the effect of washing the solvent recovery unit at intervals in order to attain high product purities with imperfect solvent recovery membranes possessing less than $100 \%$ rejection of the impurity. This operation attains a purity of $98.7 \%$ through semi-continuous operation with two washes of the solvent recovery stage, even when imperfect membranes are used in a closed-loop set-up. This contrasts favourably with the $83.0 \%$ maximum purity achievable in a similar set-up with a single continuous run. The process achieves slightly lower $(-0.7 \%)$ yield of around $98.2 \%$ compared to a continuously operated process without solvent recovery but consumes approx. $85 \%$ less solvent (theoretical analysis suggests up to $96 \%$ reduction is possible). 9 different membranes, both commercial (GMT, Novamem, SolSep) and in-house fabricated, are screened and tested on a separation challenge associated with the synthesis of macrocycles - amongst the membrane materials are polyimide (PI), polybenzimidazole (PBI) and, polyetheretherketone (PEEK). 


\section{ACCEPTED MANUSCRIPT}

\section{Introduction}

\subsection{Application of Solvent Recovery}

Organic solvent nanofiltration (OSN) is a maturing membrane-based separation technology that allows discrimination between molecules in the range of approx. $100-2,000 \mathrm{Da}$ in organic media. Some OSN membranes can also operate in harsh $\mathrm{pH}$ and temperature environments. The key features and application areas of organic solvent nanofiltration have been reviewed.[1-3]

Diafiltration is a technique commonly employed for separating two-, or multi-component mixtures using membranes, where at least one impurity is continuously washed out of a system through a selective membrane as shown in Figure 1 , with the product(s) being retained in the system. In order to keep the volume of the system constant when washing impurities through the membrane, diafiltrations require the replenishment of many multiples of the system volume with fresh solvent. 


\section{(a) Start of the diafiltration}

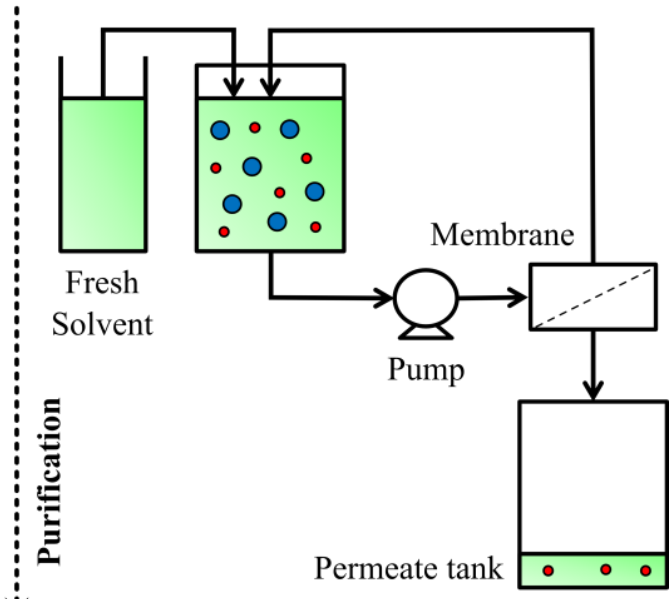

(b) End of the diafiltration

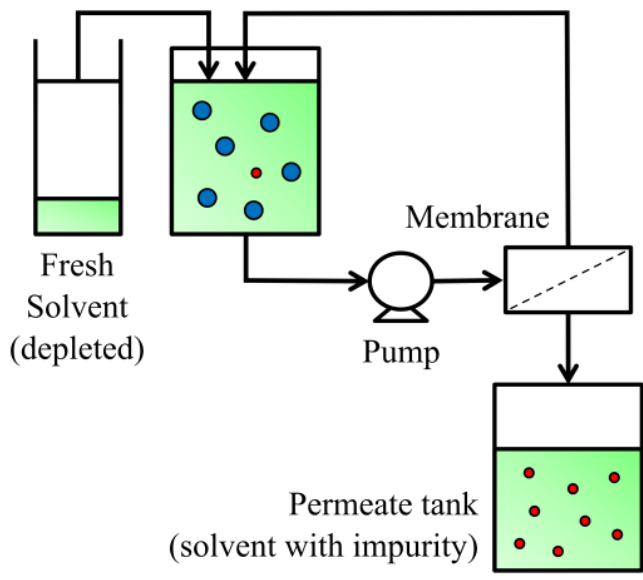

(c) Solvent recovery

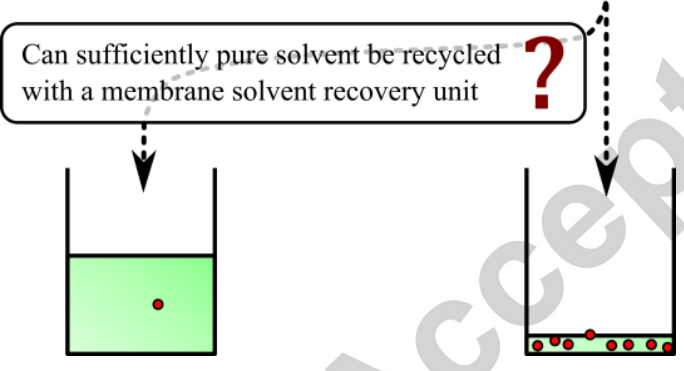

Figure 1: $\quad$ Conceptual depiction of (a) the start and (b) the end of a diafiltration process and (c) a key challenge in reducing the operational cost of diafiltrations - the recovery of solvent. A diafiltration process comprises at least two solutes and one solvent, here shown as large blue circles (product), small red circles (impurity) and green background coloration (solvent) respectively. Adapted from [1] under a Creative Commons CC-BY Usage Agreement.

Solvent throughput and disposal is typically the largest operational cost in diafiltration, and solvent recovery (SR) is therefore an increasingly sought-after concept to make processes sustainable and economically viable. Several authors have worked towards implementing some form of solvent recovery in OSN applications, with common techniques including non-selective adsorption[4, 5], hybrid distillation[6] or hybrid chromatography[7] processes, as well as recovery solely through low-molecular cut-off membranes[4, 8-11]. In most of these implementations, 


\section{ACCEPTED MANUSCRIPT}

membrane-based solvent recovery promises advantages over traditional methods of solvent recovery with regards to energy consumption and sustainability.

The main limitation of membrane-based solvent recovery is the inability of most currently available OSN membranes to retain very small impurities in the molecular weight range below $200 \mathrm{Da}$. When rejection is not absolute $(<100 \%)$, recycled solvent from a solvent recovery unit will contain some impurity which, in a closed loop system, will recirculate back into the separation stages.

In a typical diafiltration, the smallest solute that needs to be retained is the main product and rejections over $95 \%$ are usually acceptable, yielding close to quantitative product recovery in a two-stage cascade operation.[12] However, in a membrane solvent recovery operation, all solutes need to be retained and rejections as high as $99 \%$ can be insufficient for effective solvent recovery in a continuous closed-loop system, if high product purities are required. As a result, where membrane-based solvent recovery was demonstrated, the solutes to be retained were usually large enough to allow close to absolute rejection in the SR stage as summarized in Table 1. There are exceptions where solvent recovery was used in settings where some permeation of solutes is permissible, usually in closed-loop configurations. Examples include a recent cyclisation of a peptide in a high dilution reactor[10] and the MAXDEWAX process for recovery of chilled solvent from lube oil filtrates after dewaxing[13]. These and further applications such as recovery of extraction solvents e.g. from vegetable oil processing have been reviewed from an industrial viewpoint.[14]

Table 1: Typical rejections (> $99 \%$ ) for feasible membrane-based solvent recovery, and examples of applications where some solute permeation is permissible, thus allowing a lower rejection

\begin{tabular}{|c|c|c|c|c|}
\hline Macrocyclic intermediate $^{2}$ & $99.5-99.7 \%$ & THF & DuraMem $^{\mathrm{TM}} 300$ & {$[8]$} \\
\hline Triphenylmethanol & $99.8 \%$ & $\mathrm{MeOH}$ & DuraMem ${ }^{\mathrm{TM}} 150$ & [9] \\
\hline $\begin{array}{l}\text { Active Pharmaceutical } \\
\text { Ingredient }^{2}\end{array}$ & $\begin{array}{ll}\sim 600 & >99.9 \\
& 99.7-99.8 \% \\
& 99.6-99.8 \%\end{array}$ & & $\begin{array}{l}\text { Starmem }^{\mathrm{TM}} 122 \\
\text { Starmem }^{\mathrm{TM}} 240 \\
\text { Puramem }^{\mathrm{TM}} 280\end{array}$ & {$[11]$} \\
\hline Desmopressin & $1,069 \geq 96.2 \%{ }^{3}$ & $\mathrm{H}_{2} \mathrm{O}$ & $\begin{array}{l}\text { Inopor }{ }^{\mathrm{TM}} \\
0.9 \mathrm{~nm} \mathrm{TiO}_{2} \text { ceramic }\end{array}$ & {$[10]$} \\
\hline Lube oil & $\approx 98 \%^{3}$ & MEK-Toluene & Polyimide based & [13] \\
\hline
\end{tabular}

In a continuous closed-loop diafiltration where the process relies solely on a membrane to perform solvent recovery, our colleagues have found complete solvent-solute separation infeasible for a very small impurity [4]. It was observed that none of the membrane rejections were sufficiently high to perform membrane purification of the solvent containing the low molecular weight 4-(dimethylamino)pyridine impurity (MW $=122.17 \mathrm{~g}^{\mathrm{mol}}{ }^{-1}$ ).[4]

Because the mathematics for continuous operation in closed-loop diafiltration systems (as discussed in Section 3.3) dictate that high purities should not be attainable unless rejections of all species in the solvent recovery stage are close to $100 \%$ [9], we will highlight a semi-continuous workaround for these systems that allows operating with imperfect solvent recovery membranes. This will involve periodic washing of the solvent recovery unit when the impurity is most concentrated. 


\section{ACCEPTED MANUSCRIPT}

\subsection{Control of membrane cascades and implementation of solvent recovery}

With the recognition that membranes with outstanding selectivity (very tight MWCO curves, approximating stepchange rather than sigmoidal) may be unattainable, at least in the short run, much research has focused on workarounds by improving selectivity through process operation. Membrane cascades offer potentially large gains in selectivity and they were developed, often on a purely theoretical basis [15-17] although partially experimental [1823] and fully experimentally validated examples exist [4, 12, 24-27]. Much of the published work extrapolates single-stage screening results to predict and analyse the performance of multiple stages. Whilst the predictive capability for two- or three-stage cascades may actually be sufficient to warrant the conclusions drawn, there are major obstacles to industrial implementation. Beside the diminishing economic benefit of introducing additional stages[18], process control is challenging with large cascades due to the step increase in complexity and the larger number of equipment needed. Whilst in many ways considered a temperature-flexible, pressure-driven analogue of distillation, a membrane cascade shares many of the same process control problems. For each stage, fluid is pumped against pressure and conventional membrane cascades require buffer tanks and pumps capable of operating against a pressure gradient, resulting in $\mathrm{n}$ pumps and $\mathrm{n}$ buffer tanks for $\mathrm{n}$ stages, all of which have to be controlled in tandem by $\mathrm{n}$ control loops. For high recycle ratios in a 3 -stage counter-current cascade, long start-up periods were reported in at least one case (> $20 \mathrm{~h}$ until stabilisation).[27] Membrane cascade control is further complicated by the change in membrane properties with time and pressure depending on their compaction and conditioning behaviour.

\subsection{Objectives of this work}

In situ solvent recovery using membranes for diafiltration operations has been successfully demonstrated in systems where only one separation stage was coupled with a solvent recovery stage (c.f. entry 1, 2 in Table 1).[8, 9] In one example, solvent recovery was achieved due to the fact that the higher molecular weight species was the impurities, and rejections for the product and oligomer impurities in the solvent recovery stage were $\geq 99.5$ and $\geq 99.9 \%$,

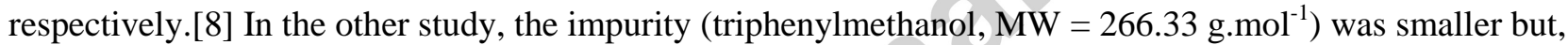
presumably due to its bulky nature, still highly rejected by the solvent recovery membranes $\left(\mathrm{R}_{\mathrm{SR}}=99.8 \%\right)$, allowing removal of $97 \%$ of the impurity in a single continuous diafiltration run.[9] It was established that in a closed loop system where rejection of the solvent recovery stage is not absolute, complete removal of the impurity cannot be achieved due to trace amounts of impurity leaching back into the separation stage. A workaround was proposed whereby the solvent recovery loop is washed out and the diafiltration process repeated to increase the impurity removal fraction. We therefore sought a solute system comprising a small impurity with incomplete rejection in the solvent recovery stage to demonstrate that solvent recovery is possible in a challenging system with this practical workaround of washing the solvent recovery stage.

Solvent recovery is demonstrated in conjunction with a two-stage separation cascade[5, 12]. The two-stage separation cascade allows us to pursue a more non-ideal separation challenge, and because it is driven by a single pressurising pump, it provides a straight-forward control strategy. However, whilst achieving higher yields, it will be shown that obtaining high purities can be more difficult with a two-stage separation cascade (compared to a single stage) when solvent recovery is performed with imperfect membranes in a closed-loop setup, because the capability of the separation stages to retain the impurity increases relative to the solvent recovery stage. Furthermore, the present work demonstrates a membrane-based solvent recovery for a real impurity, beyond the limit of currently workable systems (MW < $200 \mathrm{Da}$ ), and with a membrane material that could conceptually make a difference for real applications. Amongst screening results for a wide range of commercial membranes (Section 3.1), a recently commercialised membrane (Novamem PEEK PI 300) is presented as a candidate for solvent recovery. This membrane consists of a microporous polyetheretherketone (PEEK) support membrane coated by a thin nonporous polyimide (PI) top layer.[28, 29] The underlying mathematics of this system and the MATLAB scripts to validate the presented model for their own work are provided in the Supporting Information. 


\section{Experimental methods \& Mathematical framework}

\subsection{Solute system for separation}

In numerical terms, the preferred requirements for rejection are summarised in Table 2. Separation in a two-stage cascade is feasible for product and impurity rejections of higher than $\sim 95 \%$ and lower than around $\sim 60 \%$, respectively. It is estimated that the proposed semi-continuous workaround is applicable for solvent recovery membrane rejections of higher than $95 \%$ and thus the classic synthesis of dibenzo-18-crown-6 (3) was selected as a model system (Figure 2).[30] Preliminary screening showed that separation of the reactant, catechol (benzene-1,2diol) (1) $\left(\mathrm{M}_{\mathrm{w}}=110.11 \mathrm{~g} \cdot \mathrm{mol}^{-1}\right)$, as an impurity from the product $3\left(\mathrm{M}_{\mathrm{w}}=360.40 \mathrm{~g} \cdot \mathrm{mol}^{-1}\right)$, was feasible with several of our candidate membranes.

Table 2: Guideline rejection values for feasible demonstration of the semi-continuous workaround

\begin{tabular}{|lcc|}
\hline Membrane Stage & Product & Impurity \\
\hline Separation $\left(1^{\text {st }} \& 2^{\text {nd }}\right.$ stage $)$ & $\mathrm{x}>95$ & $60>\mathrm{x}>40^{*}$ \\
\hline Solvent recovery $\left(3^{\text {rd }}\right.$ stage $)$ & $\mathrm{x} \approx 100^{* *}$ & $99.5^{* * *}>\mathrm{x}>95$ \\
\hline
\end{tabular}

[* In an ideal separation, impurity rejection in the separation stages should be as low as possible, but we desire a value that resembles a realistic and somewhat challenging separation]

[** Although the product rejection in the solvent recovery stage will almost inevitably be higher than that of the impurity, i.e. close to absolute, product rejection in the solvent recovery stage is not relevant for this process.]

[*** In an ideal scenario, impurity rejection in the solvent recovery stage would be absolute (100\%) but in such a case no semi-continuous workaround would be needed, and such a system would therefore not be helpful for demonstrating the solution proposed in this paper.] 


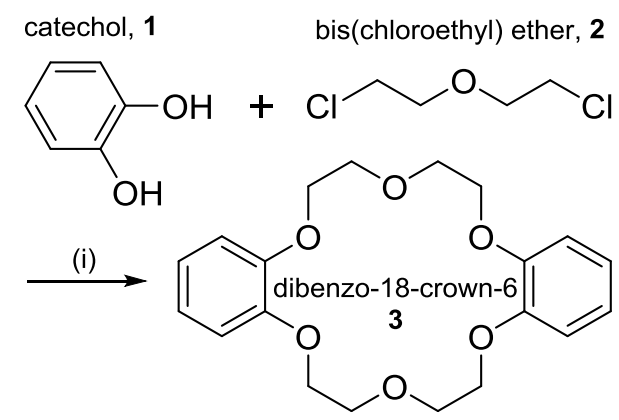

(i) base e.g. $\mathrm{OH}^{-}, \mathrm{R}-\mathrm{O}^{-}, \mathrm{H}^{-}$, solvent e.g. alcohol, tetrahydrofuran, $\Delta$

Figure 2: $\quad$ Synthesis of dibenzo-18-crown-6 from catechol and bis(chloroethyl) ether.

\subsection{Screening of OSN membranes}

Seven different OSN membranes purchased from a number of commercial suppliers were screened for suitable rejection of the model separation system of dibenzo-18-crown-6 and catechol: PEEK PI 300 (in the following referred to as PI-PEEK) from Novamem LLC (Zürich, Switzerland), GMT-NC-1, GMT-oNF1 and GMT-oNF-2 from GMT Membrantechnik GmbH (Rheinfelden, Germany), SS010206, SS010306 and SS030306 from SolSep BV (Apeldoorn, Netherlands). Furthermore, cross-linked and non-cross-linked polybenzimidazole (PBI) membranes (in the following referred to as 20PBI and 20PBI.X respectively) were prepared and screened. Solutes were dissolved in acetone $\left(1 \mathrm{~g} . \mathrm{L}^{-1}\right)$ and each membrane $\left(58 \mathrm{~cm}^{2}\right.$ per membrane coupon) was screened in cross-flow configuration with recirculation (100 L.h $\left.{ }^{-1}\right)$ at varying pressures $(10,20$ and 30 bar for most membranes). Permeate flux was measured and permeate and retentate samples were taken at steady state after approximately 4 hours of continuous operation at the given pressure.

\subsection{Polybenzimidazole (PBI) membrane fabrication}

Non-crosslinked and crosslinked polybenzimidazole (PBI) membranes were prepared based on the recent developments of solvent resistant PBI membranes by Valtcheva et al. [31, 32]. N,N-Dimethylacetamide (DMAc) and water were used as the casting solvent for the polymer and the coagulation medium (non-solvent), respectively. The dope solution for a 20PBI membrane was prepared by diluting $26 \mathrm{wt} \%$ PBI in DMAc (PBI Performance Products, USA) to $20 \mathrm{wt} \% \mathrm{PBI}$. The dope solution was mechanically stirred overnight at $25^{\circ} \mathrm{C}$ in order to homogenise the solution, and was then left to rest until all air bubbles had dispelled. The dope solutions were then cast on a polypropylene non-woven support (Novatexx 2471) using a bench top laboratory casting machine (Elcometer, UK) with an adjustable knife set at $250 \mu \mathrm{m}$, and coagulated in water at $20-22^{\circ} \mathrm{C}$. The water was replaced with isopropyl alcohol (IPA) and the pores of the membranes were preserved using PEG-400 allowing their dry storage (the A4 sheet membranes were placed in a stirred vessel containing 0.5 L of 1:1 PEG-400:IPA). Cross-linked 20PBI membranes, 20PBI.X, were prepared by immersing $0.36 \mathrm{~m}^{2}$ 20PBI membrane in $200 \mathrm{~mL} 1 \mathrm{wt} \%$, $\alpha^{\prime}$-Dibromo-pxylene (DBX) solution in acetonitrile at $75^{\circ} \mathrm{C}$ for 24 hours. 


\section{ACCEPTED MANUSCRIPT}

\subsection{Process set-up: 2-stage separation cascade plus integrated solvent recovery}

\subsubsection{Flowsheet and Equipment}

The membrane separation system consists of three stages in a closed loop configuration as shown in Figure 3 with similar equipment used in each stage. Recirculation $\left(100 \mathrm{~L} . \mathrm{h}^{-1}\right)$ was provided by GD Series Micropump gear pumps (assembled by Michael Smith Engineers, UK) with $40 \mu \mathrm{m}$ mesh inline filters upstream (Swagelok, UK). Stage pressures were monitored with mechanical pressure gauges (WIKA, Germany) and controlled using spring-loaded backpressure valves (Swagelok, UK). The first and second stage (blue and green respectively) are dedicated to separation of product and impurity in a two-stage cascade set-up with recycle, and the third stage (purple) is used for in situ solvent recovery. All stages are liquid-pressurised, with a single HPLC providing pressure by pumping from the feed tank, which is at atmospheric pressure, into the $1^{\text {st }}$ stage retentate loop. The pressure then cascades down to the $2^{\text {nd }}$ and $3^{\text {rd }}$ stage through the respective permeate flows. Downstream, the retentate backpressure flow through PCV1 and the recycle flow from the second stage through PCV2 back into the feed tank as well as the permeate flow from stage 3 are at atmospheric pressure.

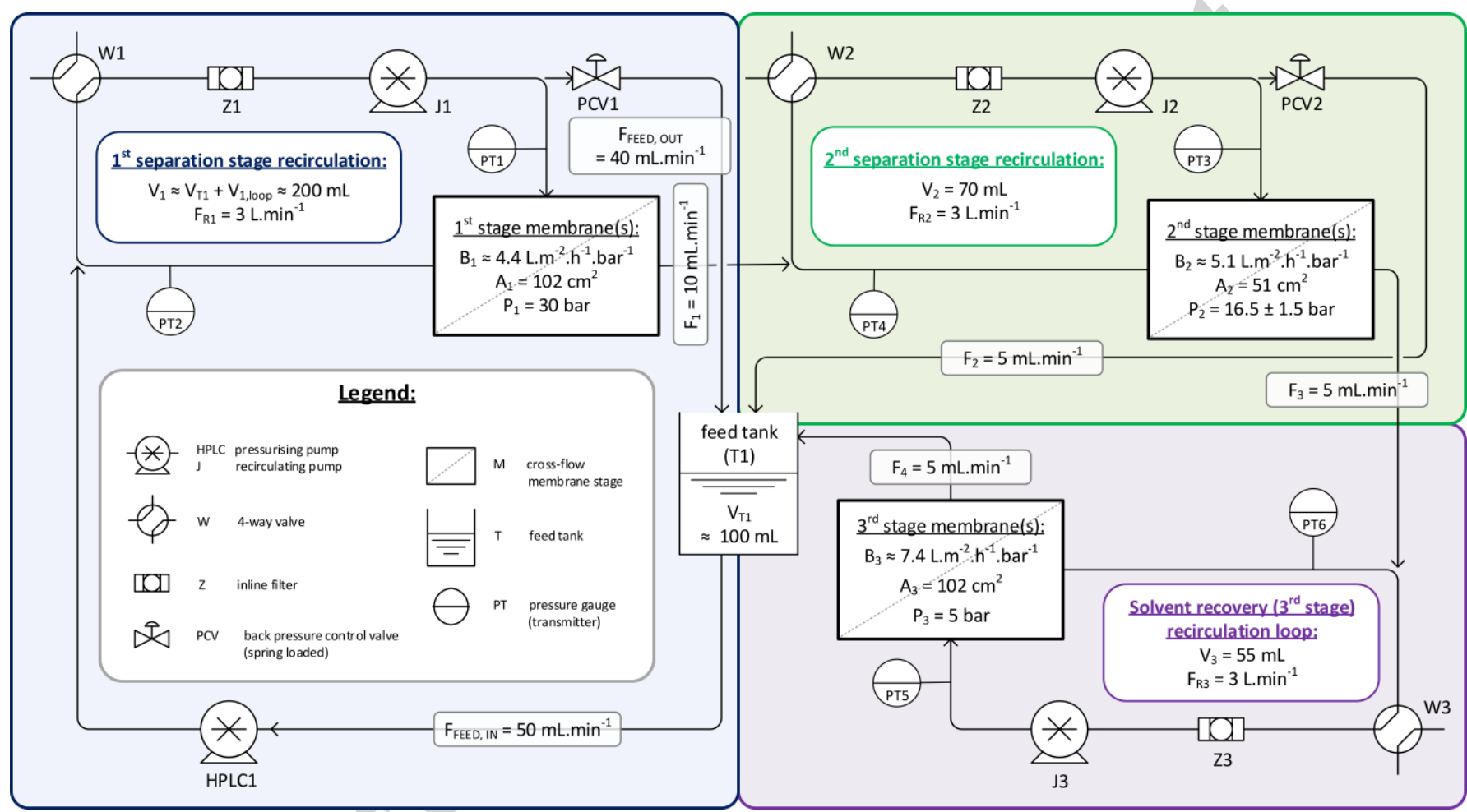

Figure 3: $\quad$ Process flowsheet for the two-stage cascade with a $3^{\text {rd }}$ stage for integrated solvent recovery

The flowrates between the stages are all interdependent and cascade performance is controlled by the recycle ratio, $\mathrm{r}_{21}$, which is defined as the fraction of stage 1 permeate flow $\left(\mathrm{F}_{1}\right)$ that is recycled back $\left(\mathrm{F}_{2}\right)$ to the feed tank from the stage 2 retentate loop through PCV2.

$$
\begin{aligned}
& r_{21}=\frac{F_{2}}{F_{1}}=\frac{F_{2}}{F_{2}+F_{4}} \\
& \dot{V}=\frac{F_{1}}{\left(\frac{1}{1-r_{21}}\right)}=\frac{F_{2}}{\left(\frac{r_{21}}{1-r_{21}}\right)}=F_{3}=F_{4}
\end{aligned}
$$

Equation 1

Equation 2

From a process control point of view, the closed-loop configuration of this set-up simplifies diafiltration operation as fresh solvent addition does not have to be controlled in tandem with diafiltration progress. However, it poses some 


\section{ACCEPTED MANUSCRIPT}

additional strategic challenges associated with the requirement to operate this system semi-continuously, if high purities are to be achieved. A detailed discussion of the control strategy for this system can be found in the Supporting Information.

The recirculating flow rates $\left(\mathrm{F}_{\mathrm{R} 1}, \mathrm{~F}_{\mathrm{R} 2}, \mathrm{~F}_{\mathrm{R} 3}\right)$ are significantly larger than the flows between stages so that all stages can be considered well-mixed. For a sufficiently rapid exchange between the feed tank and the stage 1 retentate loop, i.e. much faster exchange compared to the flow between stages $\left(\mathrm{F}_{\mathrm{FEED}, \mathrm{IN}}>\mathrm{F}_{1}\right)$, the feed tank and stage 1 retentate loop can be approximated by one well-mixed volume:

$$
\begin{array}{ll}
V_{1} \approx V_{T 1}+V_{1, \text { retentate loop }} & \text { Equation } 3
\end{array}
$$

The concentrations in the $1^{\text {st }}$ stage retentate loop are lower than those in the feed tank, by about $2 \%$ for the crown ether product, and by about $20 \%$ for the catechol impurity (tabulated data is available in the SI). The substantial difference in behaviour between crown ether and catechol is due to the much faster movement of the catechol impurity through the stages, which is due to its lower rejection by the membranes. In effect, for equal volumes in the feed tank and stage 1 retentate loop $\left(\mathrm{V}_{\mathrm{T} 1}=\mathrm{V}_{1, \text { loop }}\right)$, a $20 \%$ difference in concentration between feed tank and loop would mean a deviation of around $10 \%$ from the value of a well-mixed system in each compartment. This difference could be mitigated in practise by using a larger HPLC pump head, i.e. flow rate (e.g. $100 \mathrm{~mL}$. $\mathrm{min}^{-1}$ instead of 50 $\mathrm{mL} \cdot \mathrm{min}^{-1}$ ) or eliminated altogether by using a gas-pressurised $1^{\text {st }}$ stage but this would introduce the related hazards and make sampling difficult.

To model this liquid-pressurized system more accurately by considering the feed tank and $1^{\text {st }}$ stage retentate loop separately requires an additional simultaneous equation (for the feed tank) and two additional parameters $\left(\mathrm{V}_{\mathrm{T} 1}\right.$ and $\left.\mathrm{F}_{\mathrm{Feed}, \mathrm{in}}\right)$. An analytical solution to this system is much more computationally expensive but possible with a numerical ODE solver (manipulation of a $4 \times 4$ instead of a $3 \times 3$ matrix). Stage 1 retentate variables are plotted as values of a pseudo well-mixed stage back-calculated from the actual concentrations in the feed tank and stage 1 retentate loop. Yields and purities are based on the actual masses in the separate compartments $\left(\mathrm{V}_{\mathrm{T} 1}, \mathrm{~V}_{1, \text { loop }}\right.$ and $\left.\mathrm{V}_{2}\right)$. Assuming a well-mixed and combined $1^{\text {st }}$ stage, stripped down to display only the information required for modelling this system, the system diagram can be depicted as shown in Figure 4.

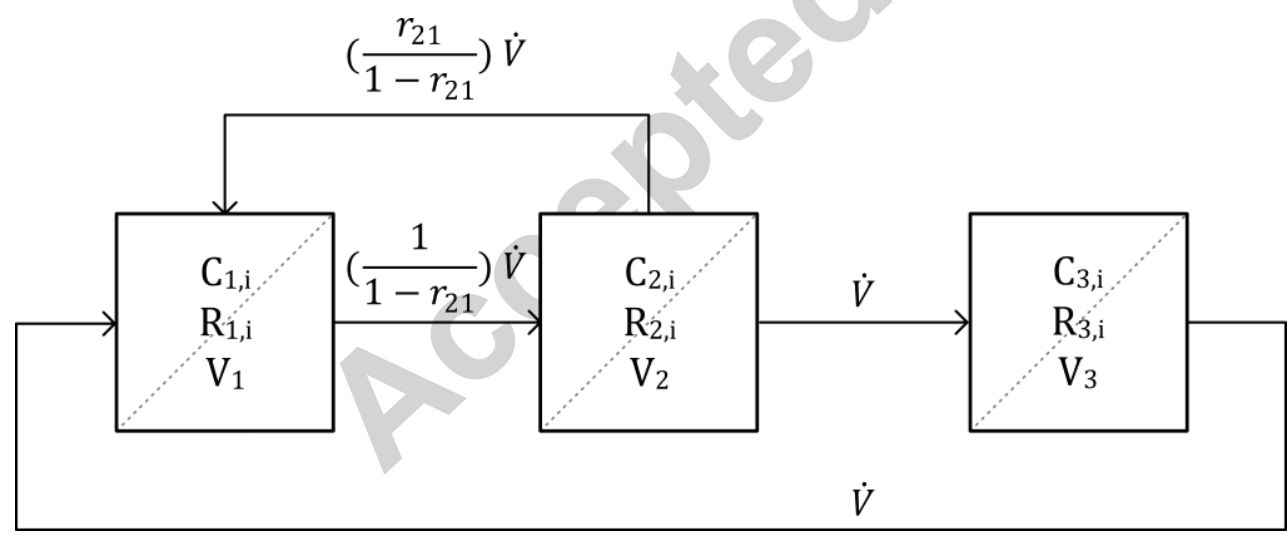

Figure 4: $\quad$ Simplified diagram with all information relevant for modelling the system 


\section{ACCEPTED MANUSCRIPT}

\subsection{Mathematical framework}

\subsubsection{System of 3 simultaneous, linear, ordinary differential equations per component $\mathrm{i}$}

The system can be described by the following set of 3 simultaneous, linear differential equations for each component $\mathrm{i}$ in the system. The rejections are assumed to be constant over the concentration range relevant to the system, on which the linearity of the system relies. For a system where rejections are functions of concentration, $\boldsymbol{R}_{s, i}=\boldsymbol{f}\left(\boldsymbol{C}_{\boldsymbol{s}, \boldsymbol{i}}\right)$, a non-linear system of equations is obtained and an analytical solution may not be attainable, thus necessitating the use of an ODE solver.

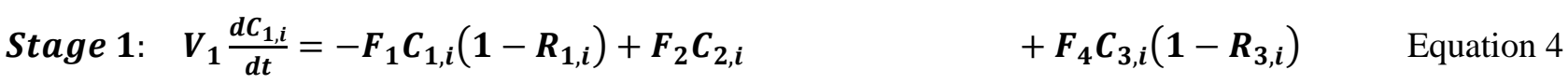

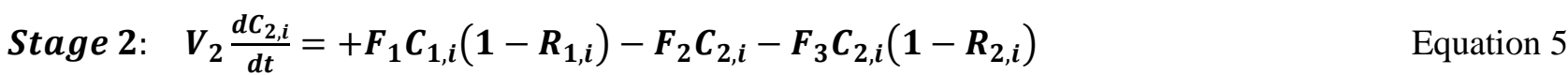

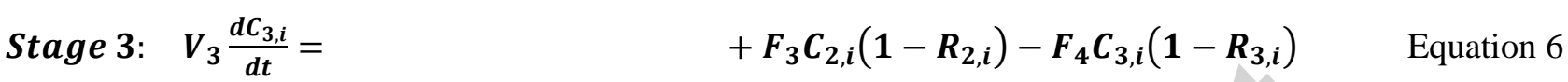

With the information on the flow balances of the system from 2.5.1, we can simplify the system to replace $F_{1}-F_{4}$ with a single flowrate, $\dot{\boldsymbol{V}}$, and the recycle ratio parameter, $\mathrm{r}_{21}$, for a dilute system where the stage volumes are constant $\left(\mathrm{V}_{1}, \mathrm{~V}_{2}, \mathrm{~V}_{3} \neq \boldsymbol{f}(\boldsymbol{t})\right)$ and the mass of solutes is insignificant compared to the mass of solvent.

$$
\text { Stage 1: } \frac{d C_{1, i}}{d t}=\frac{\dot{V}}{V_{1}}\left(-\frac{1}{1-r_{21}} * C_{1, i} *\left(1-R_{1, i}\right)+\frac{r_{21}}{1-r_{21}} C_{2, i}+C_{3, i} *\left(1-R_{3, i}\right)\right)
$$

Equation 7

Stage 2: $\frac{d C_{2, i}}{d t}=\frac{\dot{V}}{V_{2}}\left(+\frac{1}{1-r_{21}} * C_{1, i} *\left(1-R_{1, i}\right)-\frac{r_{21}}{1-r_{21}} C_{2, i}-C_{2, i} *\left(1-R_{2, i}\right)\right.$

Equation 8

Stage 3: $\frac{d C_{3, i}}{d t}=\frac{\dot{V}}{V_{3}}($

$$
\left.+C_{2, i} *\left(1-R_{2, i}\right)-C_{3, i} *\left(1-R_{3, i}\right)\right)
$$

Equation 9

where

- $\boldsymbol{C}_{\boldsymbol{s}, \boldsymbol{i}}$ denotes the concentration of compound i in stage s,

- $\boldsymbol{R}_{\boldsymbol{s}, \boldsymbol{i}}$ denotes the rejection of compound i in stage s,

- $\boldsymbol{V}_{\boldsymbol{s}}$ denotes the volume of stage s

for

○ $\mathrm{s}=1,2,3$ (stage 1, the first separation stage; stage 2, the second separation stage and stage 3 , the solvent recovery stage respectively)

○ $\quad \mathrm{i}=\mathrm{ce}$, cat (crown ether, the product compound and catechol, the impurity)

- $\quad \dot{V}$ denotes the volumetric flowrate through the system (more precisely between stage 2 and 3 and stage 3 and 1 ; see also above flowsheet)

- $\quad \boldsymbol{r}_{\mathbf{2 1}}$ denotes the recycle ratio of the separation set-up (returning flow from stage 2 back into stage 1 as a fraction of the feed entering stage 2 from stage 1 ; see also above flowsheet)

- $\mathrm{t}$ denotes time, the independent variable 


\section{ACCEPTED MANUSCRIPT}

For a single continuous diafiltration run with the start-up procedure outlined in the supporting information, the initial conditions for the system and the total mass balance for component $i$ are:

$$
\left.C_{s, i}(0)=\left(\begin{array}{c}
C_{1, i}(0) \\
C_{2, i}(0) \\
C_{3, i}(0)
\end{array}\right)=\left(\begin{array}{c}
M_{i}^{0} \\
V_{1}
\end{array}\right)\right)
$$

Equation 10

where $\boldsymbol{M}_{\boldsymbol{i}}^{\mathbf{0}}$ is the mass of component i introduced into the system at the start of the diafiltration. At the end of the diafiltration, at time t, the mass will be conserved and distributed across the stages,

$$
V_{1} C_{1, i}^{t}+V_{2} C_{2, i}^{t}+V_{3} C_{3, i}^{t}=M_{i}^{0}
$$

Equation 11

However, for an operation where a diafiltration is run for a certain period, then stopped with the volume of one of the stages being discarded, and then restarted, the initial conditions of the restarted run as well as the overall mass balance needs to reflect the mass loss of discarding. The contents of the solvent recovery stage ( ${ }^{\text {rd }}$ stage) is replaced with fresh solvent at intervals so the concentration in that stage, $\boldsymbol{C}_{\mathbf{3}, \boldsymbol{i}}^{\boldsymbol{t}}$, will be reset to zero for all components after each interval. For 'N' diafiltration intervals, lasting 'time' hours each, the mass balance is described by Equation 12.

$$
V_{1} C_{1, i}(t=N * \text { time })+V_{2} C_{2, i}(t=N * \text { time })+V_{3} \sum_{n=1}^{N} C_{3, i}(t=n * \text { time })=M_{i}^{0}
$$

Equation 12 


\section{ACCEPTED MANUSCRIPT}

\subsubsection{Solution at steady state $(\mathrm{t} \rightarrow \infty)$}

To describe upper limit for impurity removal in a single continuous run with imperfect solvent recovery mathematically, the equations in section 2.5.1 are modified to describe the system at steady state by setting $\frac{d C_{s, i}}{d t}=\mathbf{0}$.

$$
-\frac{1}{1-r_{21}} * C_{1, i} *\left(1-R_{1, i}\right)+\frac{r_{21}}{1-r_{21}} C_{2, i} \quad+C_{3, i} *\left(1-R_{3, i}\right)=0
$$

Equation 18

$$
+\frac{1}{1-r_{21}} * C_{1, i} *\left(1-R_{1, i}\right)-\frac{r_{21}}{1-r_{21}} C_{2, i}-C_{2, i} *\left(1-R_{2, i}\right) \quad=0
$$

Equation 19

$$
+C_{2, i} *\left(1-R_{2, i}\right)-C_{3, i} *\left(1-R_{3, i}\right)=0
$$

Equation 20

Rewriting these equations, direct relationships between $\boldsymbol{C}_{\mathbf{1}, \boldsymbol{i}}, \boldsymbol{C}_{2, \boldsymbol{i}}$ and $\boldsymbol{C}_{3, i}$ at steady state are obtained, which can be used to derive the mass (or mole) fraction of compound i in the third stage at steady state, $\boldsymbol{x}_{3, i}^{\boldsymbol{t}=\infty}$, as a fraction of the total mass (or mole) as given by Equation 21.

$$
\begin{gathered}
x_{3, i}^{t=\infty}=\frac{V_{3} * C_{3, i}}{V_{1} * C_{1, i}+V_{2} * C_{2, i}+V_{3} * C_{3, i}}=\frac{1}{1+\frac{V_{1}}{V_{3}} * \frac{\left(1-\left(1-r_{21}\right) * R_{2, i}\right)}{\left(1-R_{1, i}\right)} * \frac{\left(1-R_{3, i}\right)}{\left(1-R_{2, i}\right)}+\frac{V_{2}}{V_{3} * \frac{\left(1-R_{3, i}\right)}{\left(1-R_{2, i}\right)}}} \\
=\frac{1}{1+\left(1+\frac{r_{21} * R_{2, i}}{1-R_{2, i}}\right) * \frac{\phi_{3, i}}{\phi_{1, i}}+\frac{\phi_{3, i}}{\phi_{2, i}}}=\frac{1}{1+f_{C, i} \frac{\phi_{3, i}}{\phi_{1, i}}+\frac{\phi_{3, i}}{\phi_{2, i}}}
\end{gathered}
$$

Equation 21

where

$\phi_{s, i}=\frac{\left(1-R_{s, i}\right)}{V_{s}} ; f_{C, i}=\left(1+\frac{r_{21} R_{2, i}}{1-R_{2, i}}\right)$

These two parameters $-\boldsymbol{\phi}_{\boldsymbol{s}, \boldsymbol{i}}$ and $f_{\boldsymbol{C}, \boldsymbol{i}}$ - can effectively describe the impurity removal potential of this cascade system with solvent recovery.

$\boldsymbol{\phi}_{s, i}$ is the volume adjusted permeation, with units of [volume $\left.{ }^{-1}\right]$. For a multi-stage, closed-loop diafiltration system containing a given mass of a solute $\mathrm{M}_{\mathrm{i}}$, the steady state end points for distribution of that mass will depend both on the rejections of each stage as well as their volume. This is somewhat intuitive as the mass flows of solute through a membrane scale with concentration e.g. $\left(\mathbf{1}-\boldsymbol{R}_{\boldsymbol{s}, \boldsymbol{i}}\right) * \boldsymbol{C}_{\boldsymbol{s}, \boldsymbol{i}}$ and a larger stage has a relatively higher retention potential, i.e. solutes have a lower permeation potential than in a small stage because a larger stage can accommodate the same mass of solute at a lower concentration. A high $\phi$ value indicates a high potential for permeation of a solute through a membrane stage, i.e. a low capability of that stage to retain a particular solute. Hence, high $\boldsymbol{\phi}$ for our impurity in the separation stages and low $\boldsymbol{\phi}$ in the solvent recovery stage are preferable.

$f_{C, i}$ is a cascade-related parameter that amplifies the effect of the $1^{\text {st }}$ stage rejection (hence it stands as a prefactor before $\left.\phi_{3, i} / \phi_{3, i}\right)$. The inclusion of $\mathrm{r}_{21}$ in the parameter is intuitive since the recycle from the $2^{\text {nd }}$ stage back into the 


\section{ACCEPTED MANUSCRIPT}

$1^{\text {st }}$ stage means that a fraction of the solute molecules needs to pass the $1^{\text {st }}$ stage membrane more than once before being washed out of the system into the solvent recovery compartment. When no recycle is applied $\left(\boldsymbol{r}_{\mathbf{2 1}}=0\right)$, this parameter is expected to be reduced to 1 and the overall equation to simplify:

$f_{C, i}=\left(1+\frac{0 * R_{2, i}}{1-R_{2, i}}\right)=1 ;$ and $x_{i, 3}^{t=\infty}$ reduces to $=\frac{1}{1+\frac{\phi_{3, i}}{\phi_{1, i}}+\frac{\phi_{3, i}}{\phi_{2, i}}}$

\subsubsection{System \& Operator parameters}

The variables and parameters in Table 3 describe the two-component system comprising dibenzo-18-crown- 6 crown ether and catechol ( $\mathrm{i}=\mathrm{ce}$, cat).

Table 3: $\quad$ Mathematical parameters of the underlying system

\begin{tabular}{ll|lccc} 
& & & \multicolumn{2}{c}{ Bounday } & \\
\cline { 3 - 4 } Component & Unit & Type & Lower & Upper & Set \\
\hline \hline Time & {$[\mathrm{h}]$} & independent variable & 0 & & $\mathrm{t}$ \\
Concentration & {$\left[\mathrm{g} \cdot \mathrm{dm}^{-3}\right]$} & dependent variable & 0 & & $\mathrm{C}_{1, \mathrm{ce}}, \mathrm{C}_{2, \mathrm{ce}}, \mathrm{C}_{3, \mathrm{ce}}, \mathrm{C}_{1, \text { cat }}, \mathrm{C}_{2, \text { cat }}, \mathrm{C}_{3, \text { cat }}$ \\
Rejection & {[]} & system parameter & 0 & 1 & $\mathrm{R}_{1, \mathrm{ce}}, \mathrm{R}_{2, \mathrm{ce}}, \mathrm{R}_{3, \mathrm{ce}}, \mathrm{R}_{1, \text { cat }}, \mathrm{R}_{2, \text { cat }}, \mathrm{R}_{3, \text { cat }}$ \\
Stage volume & {$\left[\mathrm{dm}^{3}\right]$} & system parameter & 0 & & $\mathrm{~V}_{1}, \mathrm{~V}_{2}, \mathrm{~V}_{3}$ \\
Vol. flowrate & {$\left[\mathrm{dm}^{3} \cdot \mathrm{h}^{-1}\right]$} & operator parameter & 0 & & $\dot{\boldsymbol{V}}$ \\
Recycle ratio & {[]} & operator parameter & 0 & 1 & $\boldsymbol{r}_{\mathbf{2 1}}$ \\
\hline \hline
\end{tabular}

The volumes $\mathrm{V}_{1}, \mathrm{~V}_{2}, \mathrm{~V}_{3}$ as well as the rejections $\mathrm{R}_{1, \mathrm{ce}}, \mathrm{R}_{2, \mathrm{ce}}, \mathrm{R}_{3, \mathrm{ce}}, \mathrm{R}_{1, \mathrm{cat}}, \mathrm{R}_{2, \mathrm{cat}}, \mathrm{R}_{3, \text { cat }}$ are fixed system parameters, while the volumetric flowrate through the system $\dot{\boldsymbol{V}}$ and the recycle ratio $\mathrm{r}_{21}$ are operator controlled parameters that can be chosen at will by adjusting the pressures of stage 1 and stage 2 . This leaves two sets of three simultaneous differential equations (a set of three equations for each component), a total of six equations that describe the concentrations $\mathrm{C}_{1, \mathrm{ce}}, \mathrm{C}_{2, \mathrm{ce}}, \mathrm{C}_{3, \mathrm{ce}}, \mathrm{C}_{1, \mathrm{cat}}, \mathrm{C}_{2, \mathrm{cat}}, \mathrm{C}_{3, \mathrm{cat}}$ varying with time $\mathrm{t}$, the independent variable, according to the initial conditions $C_{1, c e}^{0}, C_{2, c e}^{0}, C_{3, c e}^{0}, C_{1, c a t}^{0}, C_{2, c a t}^{0}, C_{3, c a t}^{0}$.

If both separation stages use the same membrane - this is typically the case - the following simplification occurs: $\mathrm{R}_{1, \mathrm{ce}}=\mathrm{R}_{2, \mathrm{ce}}$ and $\mathrm{R}_{1, \mathrm{cat}}=\mathrm{R}_{2 \text {,cat. }}$. When performing purely theoretical modelling, some sensible constraints can usually be placed on the relative stage volumes (e.g. $\left.V_{1}=f\left(V_{2}, r_{21}\right)\right)$ and this is discussed in the supplementary material. However, these simplifications cannot be used for this real system as the volumes need to reflect the actual experimental set-up.

\subsubsection{Definition of other secondary parameters}

The following equations for yield, purity and removal relate to the overall system, i.e. they include both the $1^{\text {st }}$ and $2^{\text {nd }}$ separation stage. Purity is given as a weight fraction (or weight percentage). The terms for yield and removal necessarily add up to the total mass of the solute at the beginning of the diafiltration. Although yield and purity are usually defined only for products, and removal for the impurities, the equations are applicable to both (i.e. all) solutes in the system. The published MATLAB scripts and tabulated data in the SI include yield, purity and removal fractions for both crown ether and catechol to facilitate further processing. 
Yield of the crown ether product (Overall), Yield ${ }_{c e}=\frac{\left(V_{1} * C_{1, c e}^{t}+V_{2} * C_{2, c e}^{t}\right)}{\left(V_{1} * C_{1, c e}^{t=0}+V_{2} * C_{2, c e}^{t=0}\right)}$

Equation 13

Purity of the crown ether product (Overall),

$$
\text { Purity }_{c e}=\frac{V_{1} * C_{1, c e}+V_{2} * C_{2, c e}}{\left(V_{1} * C_{1, c e}+V_{2} * C_{2, c e}\right)+\left(V_{1} * C_{1, c a t}+V_{2} * C_{2, c a t}\right)}
$$

Equation 14

$$
\text { Removal of the catechol impurity (Overall), } \quad 1-\text { Yield }_{\text {cat }}=1-\frac{\left(V_{1} * C_{1, c a t}^{t}+V_{2} * C_{2, c a t}^{t}\right)}{\left(V_{1} * C_{1, c a t}^{t=0}+V_{2} * C_{2, c a t}^{t=0}\right)}
$$

Equation 15

The basis for the yield (and purity) data discussed herein are the HPLC and MS traces obtained throughout the experiment from sample taking; detailed tables of all samples taken are available in the supplementary material. Selectivity of a single stage diafiltration system can be described with regards to how purification is achieved by continuously, and preferentially, permeating the impurity out of the system. This parameter is usually referred to as permselectivity, $\alpha$

$$
\text { Selectivity for permeation of the catechol impurity (Single-pass), } \quad \alpha=\frac{\left(1-R_{1, c a t}\right)}{\left(1-R_{1, c e}\right)}=\frac{P_{1, c a t}}{P_{1, c e}}
$$

where $\boldsymbol{P}_{\boldsymbol{s}, \boldsymbol{i}}$ is there permeation parameter analogous to the opposite of rejection:

$$
\boldsymbol{P}_{s, i}=\left(1-\boldsymbol{R}_{s, i}\right), 0<\boldsymbol{P}_{s, i}<\mathbf{1}
$$

Although it is relatively straightforward to define selectivity for a single membrane stage this is not the case for a two-stage separation cascade with a recycle. It can be found empirically and theoretically that for a two-stage cascade with total recycle $\left(\mathrm{r}_{21}=1\right)$ at steady state, overall system rejection can be defined by

$$
\text { Two - stage system rejection (for total recycle at steady state), } \quad 1-\left(1-R_{1, i}\right)^{2}=1-\left(P_{1, i}\right)^{2}
$$

Equation 17

and thus selectivity for a two-stage system at steady state with total recycle should approach $\boldsymbol{\alpha}^{2}$. The relevant flow diagram and mass balance are included in the supplementary material. It should be noted that in a set-up with total recycle $\left(r_{21}=1\right)$, there is no stage 2 permeate flow and this system is therefore practically meaningless. Nevertheless, it gives an estimate for a maximum upper bound of selectivity in a two-stage system with recycle, and it can be concludes that the real selectivity for a meaningful recycle ratio $0<\mathrm{r}_{21}<1$ lies somewhere in between the two limits: $\alpha<\alpha_{\text {two-stage }}<\alpha^{2}$ 


\section{ACCEPTED MANUSCRIPT}

\section{Results \& Discussion}

\subsection{Screening and membrane selection}

Separation membranes

Overviews of the permeance and rejection performance of the screened membranes are shown in Figure 5 and Figure 6 respectively, and the corresponding values are published in tabulated format in the supporting information.

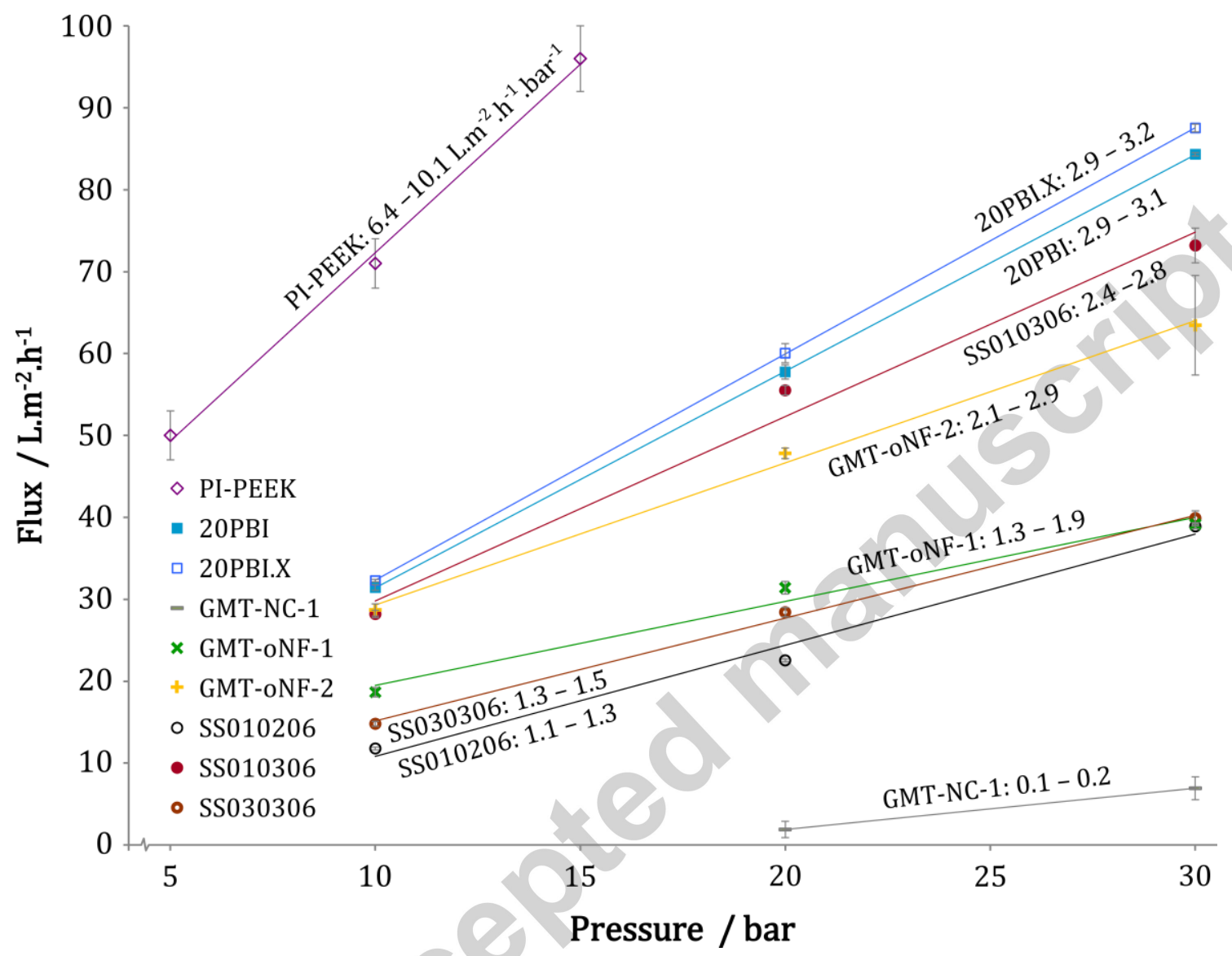

Figure 5: $\quad$ Flux data $\left[\mathrm{L} \cdot \mathrm{m}^{-2} \cdot \mathrm{h}^{-1}\right]$ in acetone with varying pressure $(5-30$ bar $)$ for different membrane types. Written alongside the fitted linear trend lines $(y=a x+b)$ are the corresponding minimum and maximum permeance values $\left[\mathrm{L} \cdot \mathrm{m}^{-2} \cdot \mathrm{h}^{-1} \cdot \mathrm{bar}^{-1}\right]$ for the screened region. The trend lines are not forced through the origin $(b \neq 0)$ and permeance is not given as a single value because permeance is not constant over the screened region for most of these membranes. Tabulated values are available in the SI.

Although suitable in terms of selectivity, several membranes showed lower flux in our acetone solvent system (GMT-oNF-1, SS030306, SS010206). Only one membrane would have been prohibitive in terms of flux which is typically used for apolar solvents (GMT-NC-1). Of the membranes with good permeance of around $2.1-3.2 \mathrm{~L} \cdot \mathrm{m}^{-2} . \mathrm{h}^{-}$ ${ }^{1}$.bar. $^{-1}$ (20PBI, 20PBI.X, SS010306 and GMT-oNF-2), all exhibited sufficient selectivity to effect the separation over a range of transmembrane pressures. In-house manufactured cross-linked PBI membrane (20PBI.X) was chosen. 


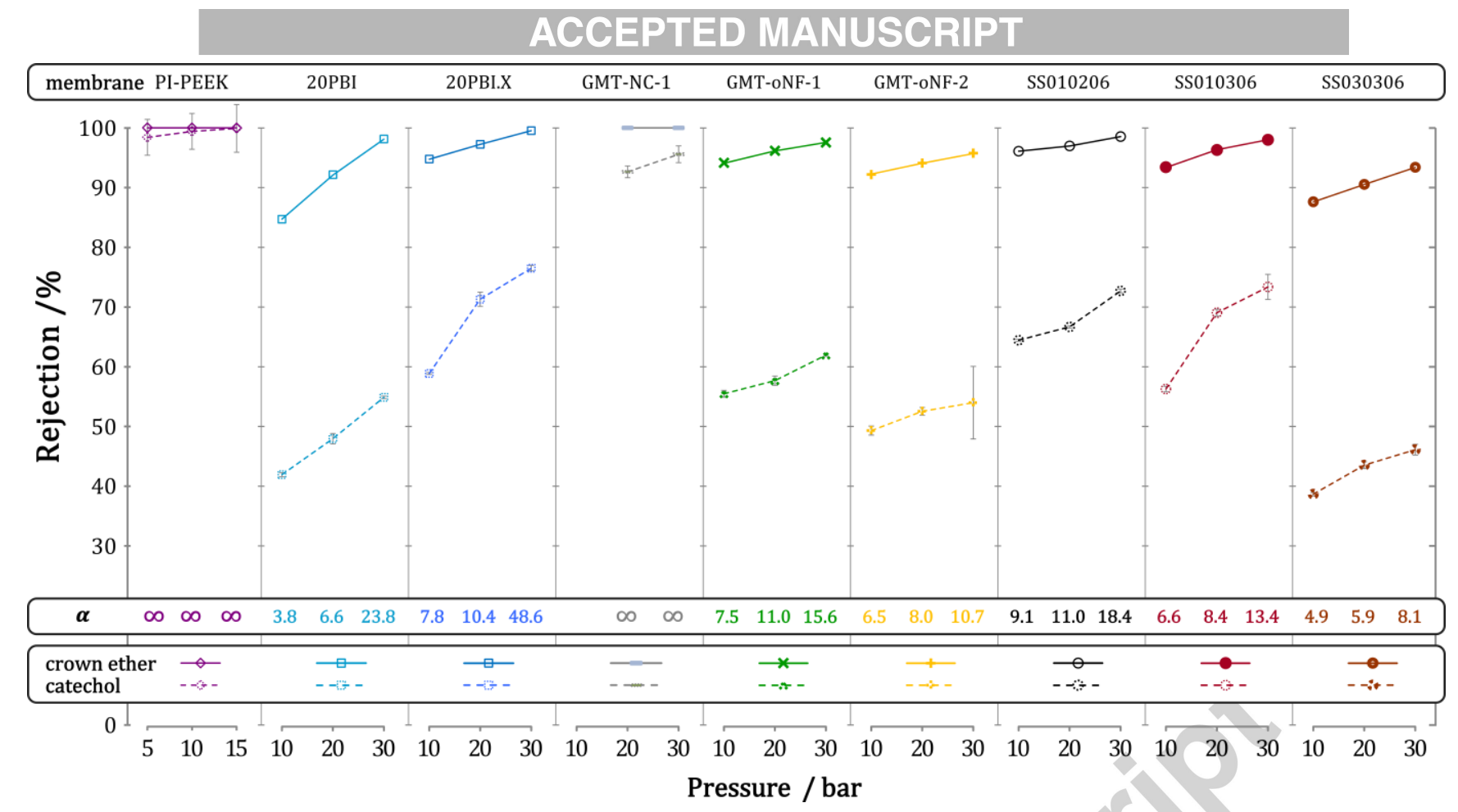

Figure 6: Rejection data for crown ether product (solid shapes, solid lines) and catechol impurity (dotted shapes, dashed lines) with varying pressure for different membrane types. Permselectivity values, $\alpha$, are shown for the corresponding rejection values and pressures according to Equation 16. Colours correspond with Figure 5.

Solvent recovery membrane

For the solvent recovery stage, it is evident from the screening data that only the PI-PEEK membrane is suitable with a sufficiently high rejection of the impurity in the desired interval $(99.5>98.4>95$, see also Table 2$)$.

However, even for an impurity rejection as high as $98.4 \%$ in the solvent recovery stage, mathematical analysis of the steady state of this system (as discussed in Section 3.3) reveals that it will not suffice to simply run this system continuously. Intermittent removal of the impurity from the solvent recovery unit will be necessary to achieve high purities. Table 4 summarises the membrane types and stage pressures used as well as the corresponding rejections which were subsequently used for modelling of all curves in the following sections.

Table 4: $\quad$ Summary of the relevant membrane parameters for the OSN diafiltration set-up. Rejection values are screened, not fitted, and permeance values are back-calculated from the experimentally measured flow-rates, and corresponding membrane areas.

\begin{tabular}{|c|c|c|c|c|c|c|c|}
\hline \multirow[t]{2}{*}{ Stage } & Membrane & $\begin{array}{c}\text { Stage } \\
\text { volume }\end{array}$ & $\begin{array}{c}\text { Absolute pressure } \\
\text { (Transmembrane } \\
\text { pressure) }\end{array}$ & $\begin{array}{c}\text { Membrane } \\
\text { area }\end{array}$ & $\begin{array}{c}\text { Permeance* } \\
\text { (Permeate } \\
\text { Flowrate) }\end{array}$ & $\begin{array}{l}\text { Crown } \\
\text { ether }\end{array}$ & Catechol \\
\hline & & $\mathrm{mL}$ & bar & $\mathrm{cm}^{2}$ & $\begin{array}{c}\mathrm{L} \cdot \mathrm{m}^{-2} \cdot \mathrm{h}^{-1} \cdot \mathrm{bar}^{-1} \\
\left(\mathrm{~L} \cdot \mathrm{h}^{-1}\right)\end{array}$ & $\%$ & $\%$ \\
\hline $1^{\text {st }}$ separation & 20PBI.X & $200^{\dagger}$ & $\begin{array}{c}30 \\
(13.5 \pm 1.5)\end{array}$ & 102 & $\begin{array}{c}4.4 \\
(0.6)\end{array}$ & 98.1 & 54.9 \\
\hline $2^{\text {nd }}$ separation & 20PBI.X & 70 & $\begin{array}{c}16.5 \pm 1.5^{* *} \\
(11.5 \pm 1.5)\end{array}$ & 51 & $\begin{array}{c}5.1 \\
(0.3)\end{array}$ & 98.1 & 54.9 \\
\hline
\end{tabular}




\section{ACCEPTED MANUSCRIPT}

\begin{tabular}{|c||c|c|c|c|c|c|c|}
\hline $\begin{array}{c}\text { Solvent } \\
\text { recovery } \\
\left(3^{\text {rd }} \text { stage }\right)\end{array}$ & PI-PEEK & 55 & $\begin{array}{c}5 \\
(4)\end{array}$ & 102 & $\begin{array}{c}7.4 \\
(0.3)\end{array}$ & 99.5 & 98.4 \\
\hline \hline
\end{tabular}

[* the permeance values shown here were back-calculated from the flow rates of the actual system by measuring the back-pressure recycle flow from stage 2 and the permeate flow of the solvent recovery stage (stage 3 ) and differ from the screening values.]

$\left[* * 2^{\text {nd }}\right.$ stage pressure was adjusted to keep the recycle ratio at 0.5 .]

[ $\uparrow$ the $1^{\text {st }}$ separation stage volume comprises the feed tank volume and the volume of the $1^{\text {st }}$ separation loop and it is approximated as a single well-mixed entity in the mathematical model.] 


\section{ACCEPTED MANUSCRIPT}

\subsection{Preliminary separation trial: continuous diafiltration for 16 hours}

To test the feasibility of the separation the three stage set-up was run for a continuous period of 16 hours. Two separate runs were conducted for validation purposes and data points for both runs are shown on the same plot. When performing solvent recovery in a closed loop set-up with imperfect solvent recovery membranes, the achievable purity in a single continuous run is limited.
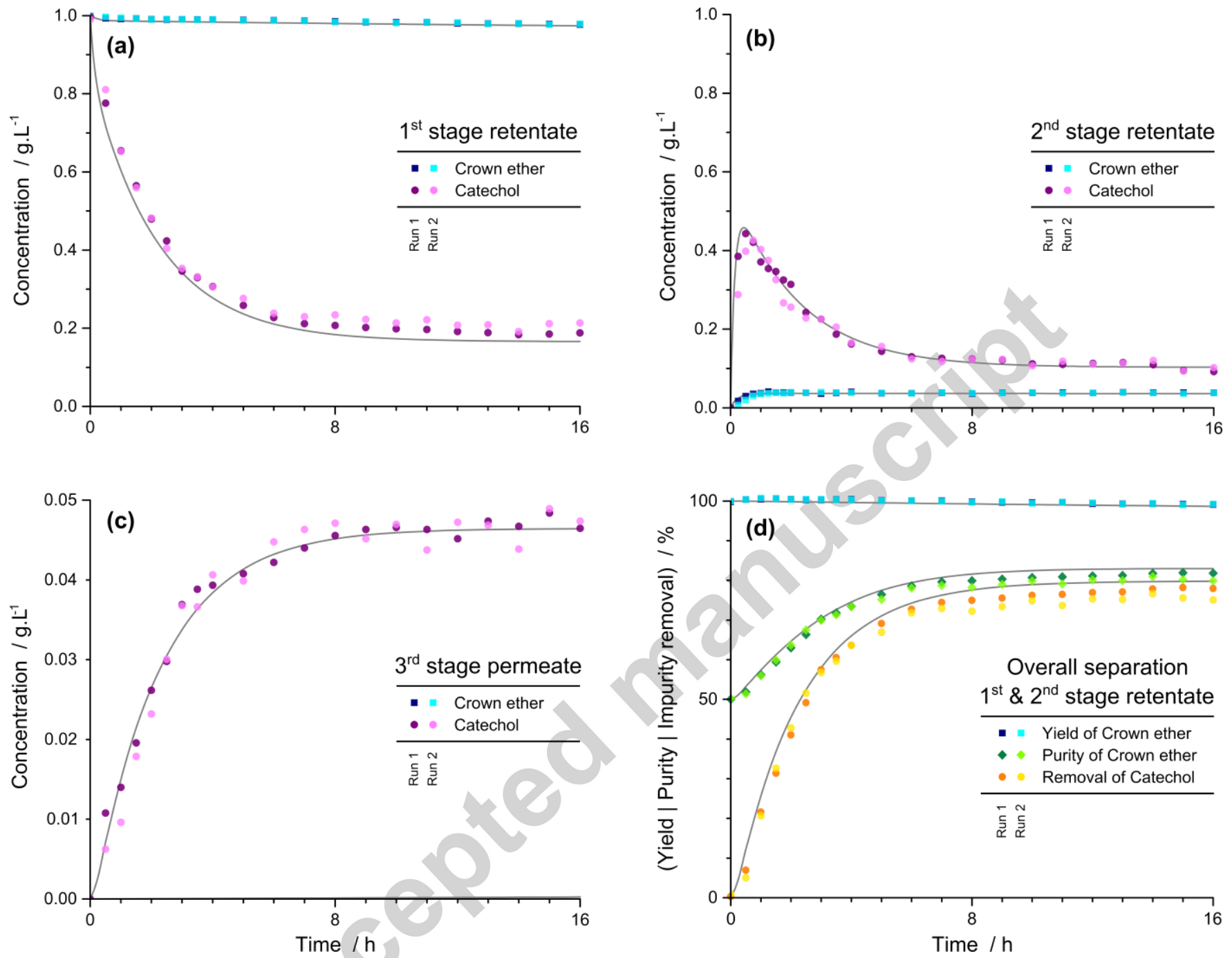

Figure 7: Concentration profiles of crown ether product (navy, teal squares) and catechol impurity (purple, pink circles) in (a) $1^{\text {st }}$ stage retentate, (b) $2^{\text {nd }}$ stage retentate and (c) $3^{\text {rd }}$ stage permeate, for two separate diafiltration runs with solvent recovery. Panel (d) shows the progress of the overall separation $\left(1^{\text {st }}\right.$ and $2^{\text {nd }}$ stage combined $)$ - yield of crown ether product (navy, teal squares), purity of crown ether product (dark green, light green diamonds) and removal of the catechol impurity (orange, yellow circles). In these two preliminary diafiltration runs, concentrations inside the solvent recovery unit $\left(3^{\text {rd }}\right.$ stage retentate) were only indirectly measured by sampling the $3^{\text {rd }}$ stage permeate (plotted in panel (c)). Underlying curves (grey) are not fitted, but modelled based on the screened values and system parameters as summarised in Table 4 using the MATLAB code supplied in the supporting information.

Figure 7 demonstrates that as the experiment progresses, progressively less catechol impurity is removed from the separation system (first two stages, panel (a) and (b)) and the catechol concentration asymptotically approaches a constant value in all three stages. This phenomenon was previously described for a two-stage system elsewhere [9]. 


\section{ACCEPTED MANUSCRIPT}

In any non-ideal solvent recovery membrane with non-absolute impurity rejection, some impurity will permeate through the $3^{\text {rd }}$ stage SR membrane back into the first stage. Thus, the system will approach a steady state $(\mathrm{t} \rightarrow \infty)$ where the mass flows of impurity (mass.time ${ }^{-1}$ ) between the stages converge to a similar value; and it then follows that the concentrations in each stage approach a constant value at the same time. The mathematical description of this steady state is outlined in Section 2.5.2.

\subsection{Strategies for optimisation}

Theoretically, a steady state exists for both the product (crown ether) as well as the impurity (catechol). In practise, due to the significantly higher rejections of the product compound compared to the impurity, in the short timeframe of the diafiltration, only the impurity approaches the steady state in any meaningful way. This is desirable as it is not in fact intended for the product compound to reach steady state, i.e. to permeate into the $3^{\text {rd }}$ stage which would be equivalent to product loss.

The key parameter for the speed of a diafiltration is the ratio of membrane area to the system volume containing the solution to be processed: $\left(\frac{A}{V}\left[\frac{m^{2}}{m^{3}}\right]\right)$ - the higher the ratio, the faster the diafiltration will proceed. Separation stage volumes $\left(\boldsymbol{V}_{\mathbf{1}}\right.$ and $\left.\boldsymbol{V}_{\mathbf{2}}\right)$ are therefore typically kept as low as practically possible to minimise diafiltration time. (but solute concentrations must not exceed the solubility limit). Similarly, rejection in the separation stages $\left(\boldsymbol{R}_{\mathbf{1}, \boldsymbol{i}}\right.$ and $\left.\boldsymbol{R}_{\mathbf{2}, \boldsymbol{i}}\right)$, and the recycle ratio, $\mathrm{r}_{21}$, will be tuned to maximise separation stage performance. $\boldsymbol{\phi}_{1, i}, \boldsymbol{\phi}_{2, i}$ and $f_{C, i}$ are therefore unlikely to be tuneable for solvent recovery. It is therefore necessary to optimise, i.e. minimise, $\boldsymbol{\phi}_{3, i}$ by maximising $\boldsymbol{R}_{3, i}$, and by adjusting $\boldsymbol{V}_{\mathbf{3}}$. The solvent recovery stage volume $\boldsymbol{V}_{\mathbf{3}}$ can be increased but at the expense of increasing solvent use at each interval during washing and refilling the solvent recovery stage - this is analogous to the classic trade-off in diafiltration whereby purity can be increased further but at the expense of higher solvent consumption. Secondly, it is important to have a solvent recovery membrane that is as impermeable to the impurity as possible, but due to the typical inverse relationship between rejection and flux, having a tighter membrane with lower permeance, $\mathrm{B}$, will require a larger membrane area, $\mathrm{A}$, for the same volumetric flow through the membrane, which is an economical trade-off. A similar reasoning is provided for a two-stage system elsewhere (page 2377).[9]

An evaluation of Equation 21 for our model reveals that for our preliminary separation trial, we should expect the $\boldsymbol{\phi}_{s, \boldsymbol{c a t}}$ parameters and maximum possible impurity removal, $\boldsymbol{x}_{\mathbf{3}, \boldsymbol{c} \boldsymbol{c} \boldsymbol{t}}^{\boldsymbol{t}=\boldsymbol{}}$, to be as follows:

$$
\begin{aligned}
\phi_{1, c a t}=\frac{451}{200} \approx & 2.255 ; \phi_{2, c a t}=\frac{451}{70} \approx 6.443 ; \phi_{3, c a t}=\frac{16}{55} \approx 0.291 ; f_{C, c a t}=\frac{1451}{902} \approx 1.609 ; x_{3, c a t}^{t=\infty} \\
& =0.7983
\end{aligned}
$$

Averaged over two experimental runs, the actual impurity removal after 16 hours, $\boldsymbol{x}_{3, \boldsymbol{c a t}}^{\boldsymbol{t}=\mathbf{h}}$, is around $76.5 \%$ which means the system is within $95.8 \%$ of the maximum attainable impurity removal at that time $\left(\frac{\boldsymbol{x}_{3, \text { cat }}^{t=16}}{\boldsymbol{x}_{3, \text { cat }}^{t=\infty}}=\frac{\mathbf{0 . 7 6 5}}{\mathbf{0 . 7 9 8 3}}=\right.$ 0.958). The model based on the screening data as plotted (solid, grey) in Figure 7 therefore slightly overestimates impurity removal, predicting that the system should be within 0.99 of the maximum attainable impurity removal after around 10.3 hours. The concentration of the impurity in the solvent recovery stage needs to be reduced to reach higher purities than possible with this closed system.

Conceptually, there are at least two strategies to approach the problem: one is to continuously bleed a small fraction of the solvent from the SR stage over the duration of the experiment - this will remove impurity from the SR stage in a CSTR model fashion, and would allow continuous operation of the system. Another method is to wash the $3^{\text {rd }}$ stage at intervals as the impurity profiles approach steady state - this necessitates operating the system semi-continuously. 


\section{ACCEPTED MANUSCRIPT}

Washing the SR stage at intervals is superior as it allows washing out the impurity in its most concentrated attainable state for any given system. The efficiency of washing during an interval and the eventual solvent saving will depend on how many multiples of the solvent recovery stage volume of pure solvent will be needed to reduce the material concentration in the SR stage back down or close to zero. If the solvent recovery stage is to be washed in one continuous flush during an interval, the efficiency of washing will depend on how closely the solvent recovery stage resembles a plugged flow reactor (PFR). For an ideal PFR, the solvent consumption per diafiltration would be merely the volume of the solvent recovery stage (i.e. a multiple of 1) but in practise more solvent may be needed. Another way of washing the solvent recovery stage would be several cycles of draining the contents, and then refilling with pure solvent and recirculating briefly before draining again. In that case, the exact quantity will depend on how welldesigned the solvent recovery stage is for draining e.g. whether it can be fully drained and whether the membranes are stable enough to allow flushing the system with air for a brief period.

Washing experiments were carried out to confirm workability of the latter method of several washing cycles, in which the solvent recovery stage was filled with a solution of catechol at a concentration of 2.7 g.L $\mathrm{L}^{-1}$. The solution was circulated briefly without permeate flow, and then drained and the loop briefly flushed out with air. In one case, the stage was immediately refilled with pure solvent and, after recirculation, the residual catechol concentration was measured as 0.038 g.L. $\mathrm{L}^{-1}$ equivalent to around $1.39 \%$ of the original solution content. In another case, after draining, only the membrane cell within which most of the residual impurity was suspected was additionally rinsed with around $5 \mathrm{~mL}$ of solvent before refilling the loop with fresh solvent and recirculating, and in this case the residual catechol concentration was only 0.019 g.L $\mathrm{L}^{-1}$ or $0.68 \%$ of the original. Therefore, even for a conservative estimate of a poorly designed loop where $5 \%$ of the original mass remains in the loop after each washing cycle, three washing cycles should leave only around $0.01 \%$ of the original concentration. Therefore the solvent consumption per washing cycle is estimated to be between 1 and 3 times the volume of the solvent recovery stage, $V_{3}$, and this is reflected in Figure 9, where both the higher and the minimum estimates are plotted. It is worth noting that not all impurity would actually have to be removed from the SR stage as long as a significant reduction is achieved. In an industrial setting, it is clearly desirable to minimise the volume of washing solvent, most likely at the expense of not reducing the concentration in stage 3 to exactly 0 .

\subsection{Increasing purity further: repeated washing of the SR stage at appropriate intervals ( $3 \times 8$ hours of diafiltration)}

A further reduction of the impurity level in the system can be achieved from the single continuous run by washing out the solvent recovery (SR) stage and thus removing a large fraction of the total impurity from the system entirely whilst resetting the concentration of impurity (and product) in the SR stage to zero. Further reduction of impurity (i.e. further increase in product purity although not exactly analogous) is demonstrated by washing at intervals after 8 hours of diafiltration as it is evident from the preliminary data in Figure 7 that the system is approximately at steady state after 8 hours. Two repeat experiments were run with 8 hours of diafiltration, followed by washing of the SR stage and another 8 hours of diafiltration, followed by another washing of the SR stage and yet another 8 hours of diafiltration - the key data at each stop point is summarised in Figure 8. An exhaustive table including concentration data points is given in the supplementary material. 

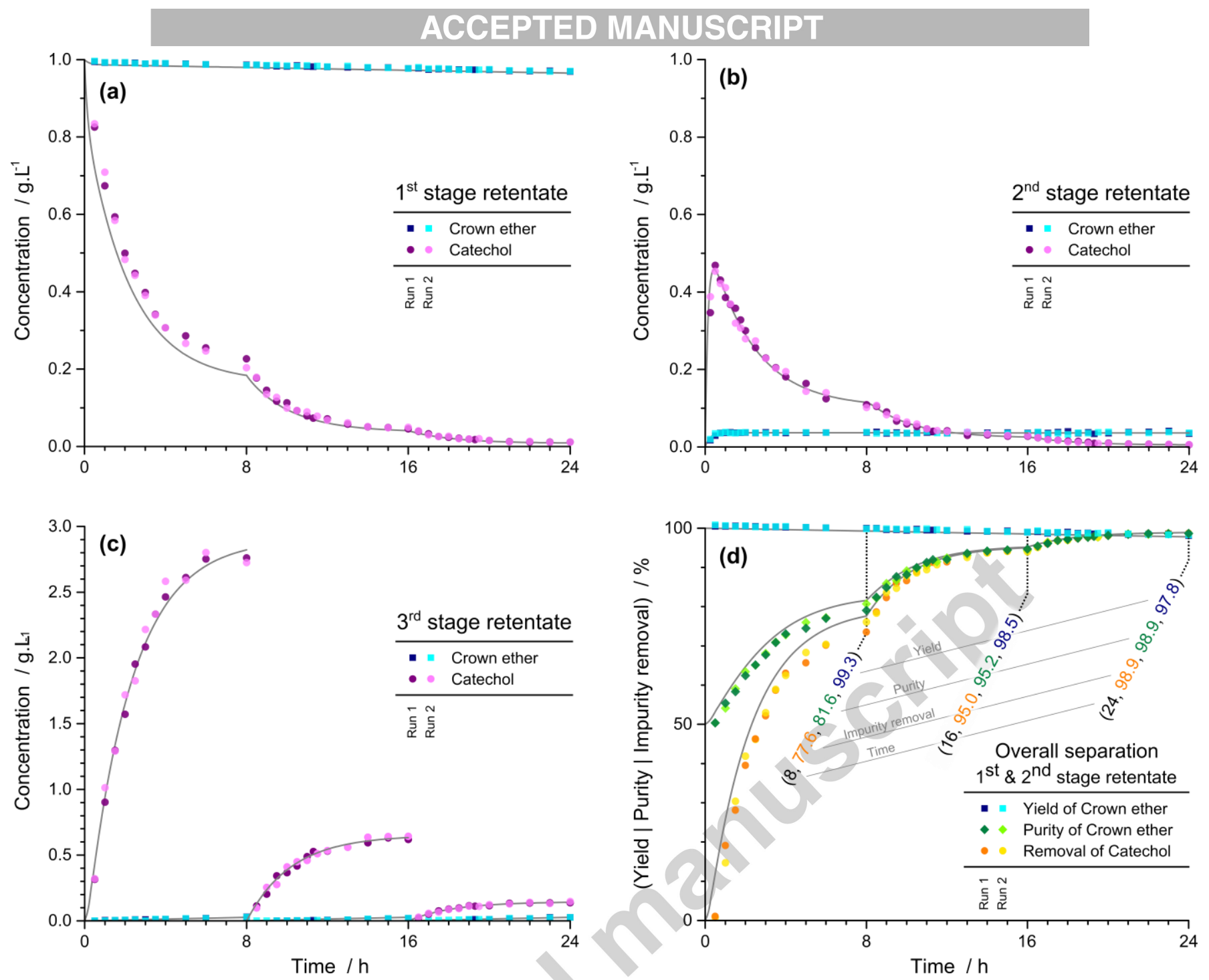

Figure 8: $\quad$ Concentration profiles of crown ether product (navy, teal squares) and catechol impurity (purple, pink circles) in (a) $1^{\text {st }}$ stage retentate, (b) $2^{\text {nd }}$ stage retentate and (c) $3^{\text {rd }}$ stage retentate for two separate diafiltration runs with solvent recovery over a period of 24 hours ( $3 \times 8$ hours with intermittent washing of the solvent recovery stage). Panel (d) shows the progress of the overall separation $\left(1^{\text {st }}\right.$ and $2^{\text {nd }}$ stage combined) - yield of crown ether (navy, teal squares), purity of crown ether (dark green, light green diamonds and removal of catechol impurity (orange, yellow circles). Underlying curves (grey) are not fitted, but modelled based on the screened values and system parameters as summarised in Table 4 using the MATLAB code supplied in the supporting information. Values (shown in brackets) at the end of each diafiltration interval shown in panel (d) are modelled, not experimental values.

Figure 8 shows that the washing procedure successfully facilitates impurity removal to a much higher degree than would be possible without washing. A theoretical value for maximum total removal is given by $\mathbf{1}-\left(\mathbf{1}-\boldsymbol{x}_{3, \text { cat }}^{\boldsymbol{t}=\infty}\right)^{\boldsymbol{n}}$ where $\mathrm{n}$ is the number of diafiltration intervals starting with pure solvent in the solvent recovery stage (or number of washes -1$)$, and $\boldsymbol{x}_{\mathbf{3}, \text { cat }}^{\boldsymbol{t} \boldsymbol{t}}$ is the maximum removal per run as defined above. Where only a removal of $79.8 \%$ (1$\left.(1-\mathbf{0 . 7 9 8 3})^{\mathbf{1}}\right)$ of the impurity is possible with a single diafiltration run (i.e. infinitely long) due to the imperfect nature of the solvent recovery membrane, three separate consecutive runs with intermediate washing of the solvent recovery stage allow a reduction by $99.2 \%\left(\mathbf{1}-(\mathbf{1}-\mathbf{0 . 7 9 8 3})^{3}\right)$. As it is not practical to run a diafiltration infinitely long, and due to the nature of diminishing returns with approximately constant product loss over time, it is recommended to remove only a large fraction of the maximum impurity removal possible in each interval. Therefore, 


\section{ACCEPTED MANUSCRIPT}

it is more suitable to mathematically define $\mathbf{1}-\left(\mathbf{1}-\boldsymbol{\beta} * \mathbf{x}_{3, \text { cat }}^{\mathbf{t}=\infty}\right)^{\mathbf{n}}$ where $\beta$ denotes the actual removal as a fraction of the maximum removal possible. In the presented case study each diafiltration interval was for 8 hours, which corresponds to a removal of $97.2 \%(\beta=0.972)$ of the possible maximum removal per interval. After three 8 hour diafiltration intervals, a total impurity removal of around $98.9 \%\left(\mathbf{1}-(\mathbf{1}-\mathbf{0 . 9 7 2} * \mathbf{0 . 7 9 8 3})^{\mathbf{3}}\right)$ is expected. A removal of $98.7 \%$ averaged over two separate runs was experimentally measured which corresponds well with the modelled prediction $(-0.2 \%)$.

\subsection{Solvent consumption}

It has been demonstrated that the introduction of a membrane-based solvent recovery stage has made continuous impurity removal more difficult but crucially it allows a significant reduction in fresh solvent that needs to be fed through the system. A two-stage system without solvent recovery can be empirically compared and the diafiltration time required to reach a similar purity of $98.9 \%$ for similar process parameters can be estimated. It takes approximately 12.6 hours of continuous diafiltration to attain similar purity without solvent recovery and in that time approximately $3.8 \mathrm{~L}$ of solvent would need to be fed through the system, which is the equivalent of 69 multiples of the solvent recovery stage volume.

In contrast, three washings of the solvent recovery stage (a wash is required at the end of the last run) would ideally only consume $0.165 \mathrm{~L}$ (i.e. a multiple of 3,1 multiple per wash, $96 \%$ reduction in solvent consumption). The real solvent consumption depends on how easily the solvent recovery stage can be washed and how closely it resembles a PFR. Nevertheless, even when as much as three times the SR stage volume is used per wash (total approx. 0.495 L, 9 multiples), the overall solvent consumption is over $85 \%$ lower with an integrated solvent recovery stage as used in this set-up. Washing the majority of impurity out of the SR recovery stage each time is sufficient, and it is not necessary to remove absolutely all impurity in each wash. 


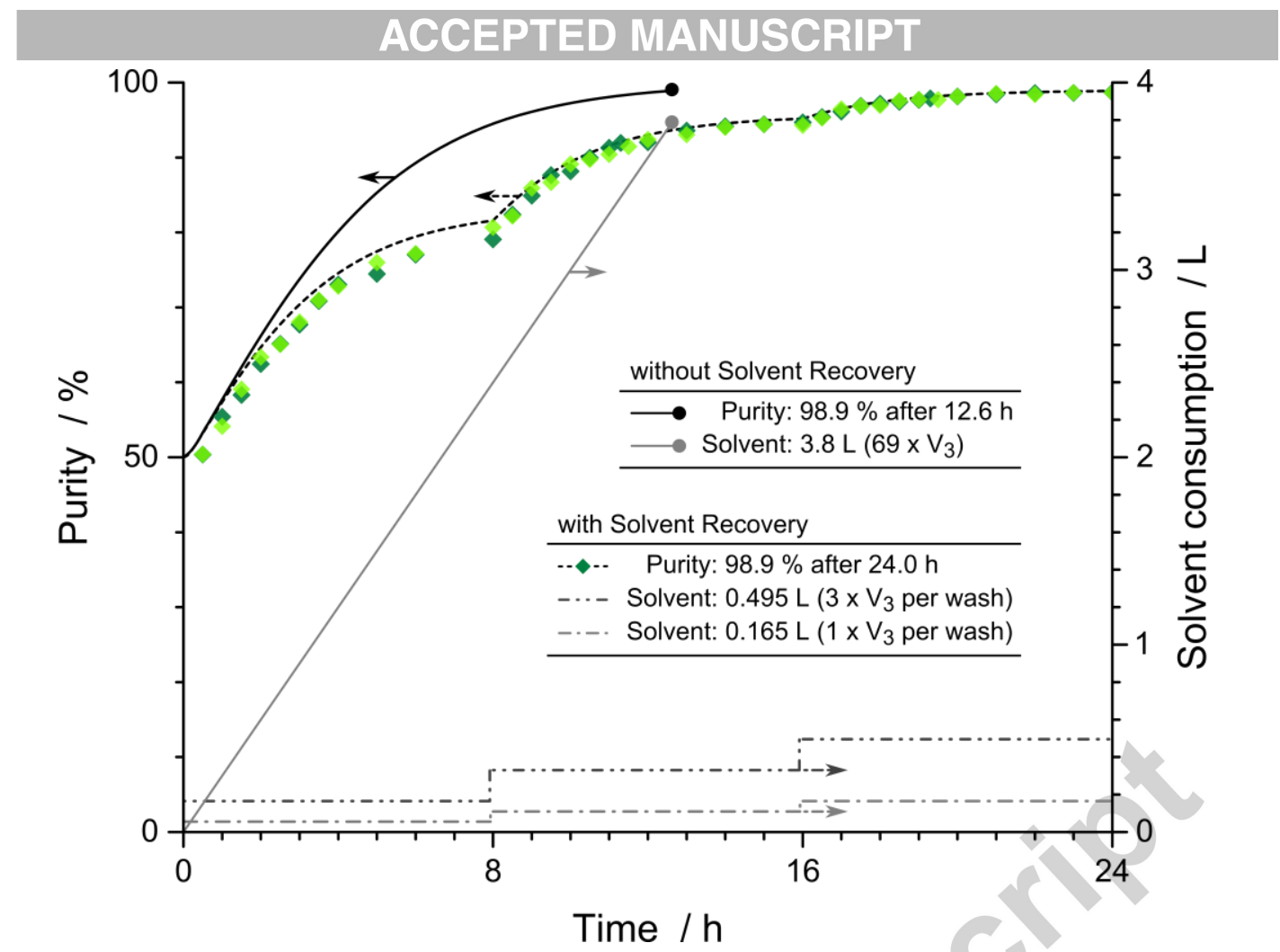

Figure 9: Comparison of solvent consumption between a system with solvent recovery and a system without solvent recovery: Purity (solid, black) of $98.9 \%$ is attained after 12.6 hours with solvent consumption (solid, grey) of $3.8 \mathrm{~L}$ for a system without solvent recovery. For a system with solvent recovery, the same purity (light green, dark green diamonds, dashed black line) of $98.9 \%$ is attained after a longer period of 24 hours but with a significantly lower solvent consumption (dash dot dot, grey) of around $0.495 \mathrm{~L}$ for washing with three multiples of the solvent recovery stage volume, $\mathrm{V}_{3}$, per diafiltration interval. The theoretical minimum solvent recovery (dash dot, light grey) is $0.165 \mathrm{~L}\left(1 \times \mathrm{V}_{3}\right.$ per wash). Purity curves with solvent recovery are not fitted, but modelled based on screening data analogous to Figure 8.

\subsection{Maximum purity as a better guideline}

There is a more subtle point regarding the appropriate point to wash the SR stage. From the concentration profiles, it is apparent that the impurity will reach steady state, i.e. accumulate in the SR stage quicker than the desired product. Therefore, at a point in time when almost all impurity that can be removed is removed from the separation stages into the SR stage, the product will still permeate into the SR stage at about the same rate as at the beginning of the diafiltration (as its concentration in the first two stages is relatively constant after a brief period at the start of the diafiltration). For any non-ideal separation where the rejection of the product in the separation stages i.e. the $2^{\text {nd }}$ separation stage is not absolute $\left(\mathbf{R}_{2, \text { ce }}<1\right)$, the purity of the product (combined mass of product in the first two stages / combined mass of product and impurity in the first two stages) will move through a maximum and actually decrease again after a certain point.

Overall purity of product crown ether in the separation stages is given by

Purity $_{\text {ce }}=\frac{\mathrm{V}_{1} * \mathrm{C}_{1, \mathrm{ce}}+\mathrm{V}_{2} * \mathrm{C}_{2, \mathrm{ce}}}{\left(\mathrm{V}_{1} * \mathrm{C}_{1, \mathrm{ce}}+\mathrm{V}_{2} * \mathrm{C}_{2, \mathrm{ce}}\right)+\left(\mathrm{V}_{1} * \mathrm{C}_{1, \mathrm{cat}}+\mathrm{V}_{2} * \mathrm{C}_{2, \mathrm{cat}}\right)}$ 


\section{ACCEPTED MANUSCRIPT}

When looking at the purity graph corresponding to the diafiltration system above, this is not immediately obvious due to the high overall rejection of the product in the separation stages. Nevertheless, closer inspection of the change of purity (differential of purity with time) reveals that if the diafiltration in Figure 7 was to be run without washing for more than 16 hours, purity would actually decrease again as shown in Figure 10.

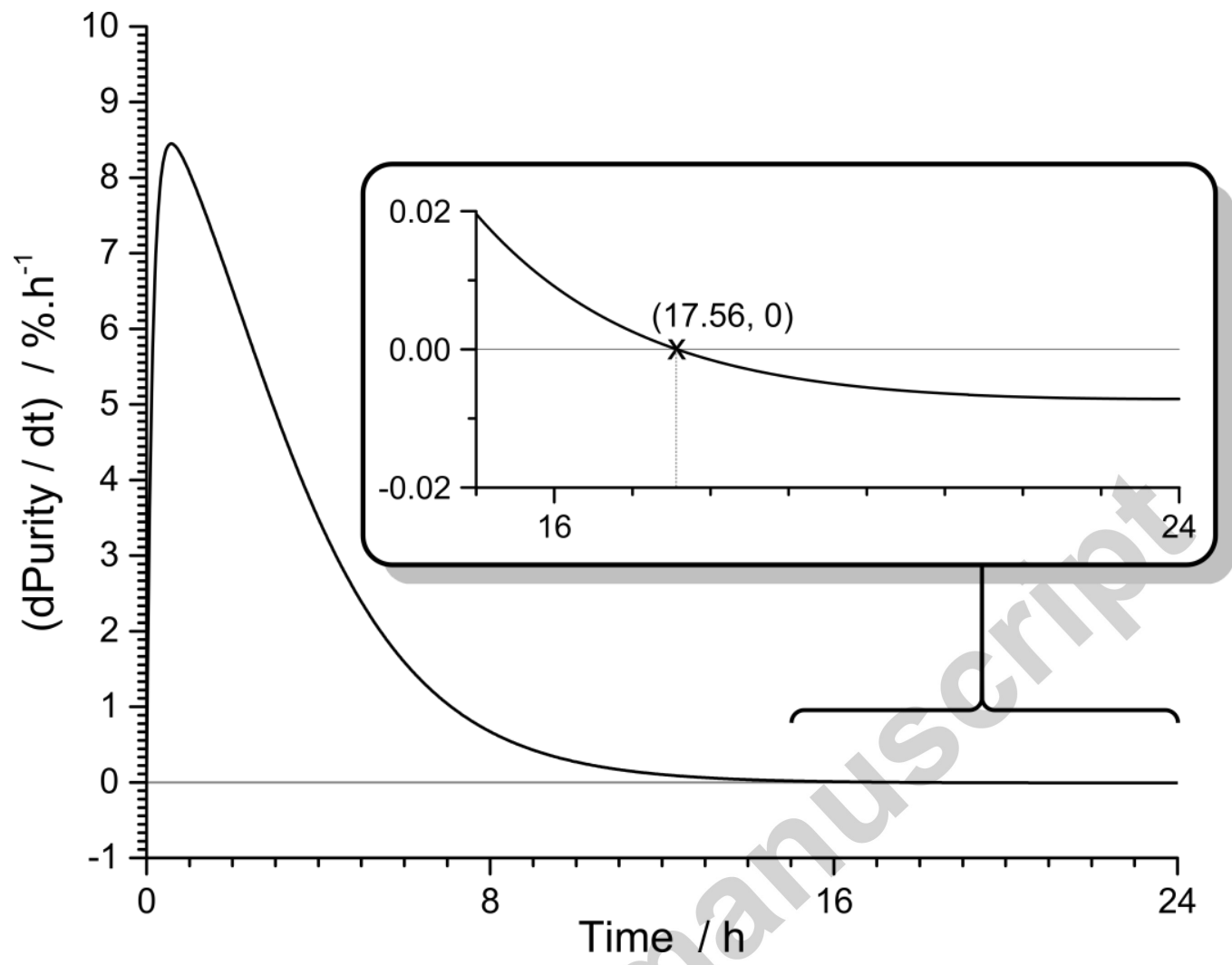

Figure 10: $\quad$ Change of purity for an overlong diafiltration of the model system highlighting the presence of a maximum attainable purity at around 17.56 hours after which purity will decrease again

Therefore the washing procedure needs to be initiated after a certain fraction of the maximum attainable purity has been reached and not relative to the steady state impurity removal fraction, i.e. wash when $\mathrm{P}=\left(\gamma * \mathrm{P}_{\max }\right)$ not according to $\mathrm{x}_{\mathrm{b}, 3}=\left(\beta * \mathrm{x}_{3, \mathrm{cat}}^{\mathrm{t}=\infty}\right)$. In a scenario where a (continuous) correlation is known for purity of a product and the corresponding price, the optimum point can actually be found i.e. $\gamma$ can be defined accurately. There is necessarily a trade-off between yield and purity because even as purity still increases towards the maximum attainable purity, yield is continuously decreasing at an approximately constant rate. However, in all cases it recommended to stop the diafiltration before the maximum achievable purity per run is attained. The discrepancy between impurity removal and actual increase in purity will be more pronounced for a system with lower selectivity, i.e. where product rejection in the separation stages is lower for a similar impurity rejection. 


\section{Conclusions}

In this work, we demonstrated that high product purities can be achieved in a two-stage cascade diafiltration with integrated solvent recovery, even when the solvent recovery membranes do not exhibit absolute rejection of the impurity. Close to absolute rejections previously deemed to be a prerequisite for feasible membrane-based solvent recovery. It has been shown that excellent impurity removal is possible from a two-stage separation cascade with a PI-PEEK solvent recovery membrane stage exhibiting only $98.4 \%$ cut-off for catechol, a challengingly small impurity.

Continuous operation would only allow a maximum removal of around $79.8 \%$ but washing of the solvent recovery stage circumvents this limitation. Removal of $98.7 \%$ of the impurity was achieved with a total of two washes between $3 \times 8$ hours of diafiltration, with product yield and purity of $98.2 \%$ and $98.7 \%$ respectively. Further removal is possible by increasing the number of washing steps and continuing diafiltration in a similar manner.

The additional impurity removal comes at a trade-off with processing time, and a marginal increase in solvent consumption. The impurity is removed in a semi-continuous fashion when it is most concentrated in the solvent recovery stage. Overall solvent consumption of the system with integrated solvent recovery is a fraction (approximately $85 \%$ lower) of a two-stage cascade without recovery. The proposed workaround may therefore help to mitigate solvent consumption and solvent disposal, one of the cost contributors of diafiltration, and thereby render OSN diafiltrations more sustainable and competitive.

The work also highlights the leanness and simplicity of control of this type of cascade (two-stage separation plus in situ solvent recovery) which achieves high yield and purity for a challenging separation but with a minimum of equipment.

\section{Acknowledgements}

Financial support has been provided by the EPSRC under grant code EP/K502856/1 (DTA for M. Schaepertoens) and by the School of Chemical Engineering \& Analytical Science, The University of Manchester (PhD scholarship for C. Didaskalou). The authors wish to thank Elisabeth Davenport (University of Manchester, UK) for her assistance with analytical techniques and Raúl Sánchez Galán (University College London, UK) for discussions on the underlying mathematics. The authors are grateful to Patrizia Marchetti, Marcus Cook and Piers R.J. Gaffney (all Imperial College London, UK) for proofreading the manuscript at various stages. Any mistakes remain those of the authors. 


\section{References}

[1] P. Marchetti, M.F. Jimenez Solomon, G. Szekely, A.G. Livingston, Molecular Separation with Organic Solvent Nanofiltration: A Critical Review, Chemical Reviews, 114 (2014) 10735-10806.

[2] G. Szekely, M.F. Jimenez-Solomon, P. Marchetti, J.F. Kim, A.G. Livingston, Sustainability assessment of organic solvent nanofiltration: from fabrication to application, Green Chemistry, 16 (2014) 4440-4473.

[3] P. Vandezande, L.E.M. Gevers, I.F.J. Vankelecom, Solvent resistant nanofiltration: separating on a molecular level, Chemical Society Reviews, 37 (2008) 365-405.

[4] L. Peeva, J.d.S. Burgal, I. Valtcheva, A.G. Livingston, Continuous purification of active pharmaceutical ingredients using multistage organic solvent nanofiltration membrane cascade, Chemical Engineering Science, 116 (2014) 183-194.

[5] J.F. Kim, G. Szekely, I.B. Valtcheva, A.G. Livingston, Increasing the sustainability of membrane processes through cascade approach and solvent recovery-pharmaceutical purification case study, Green Chemistry, 16 (2014) 133-145.

[6] J. Micovic, K. Werth, P. Lutze, Hybrid separations combining distillation and organic solvent nanofiltration for separation of wide boiling mixtures, Chemical Engineering Research and Design, 92 (2014) 2131-2147.

[7] S. Nimmig, M. Kaspereit, Continuous production of single enantiomers at high yields by coupling single column chromatography, racemization, and nanofiltration, Chemical Engineering and Processing: Process Intensification, 67 (2013) 89-98.

[8] I. Sereewatthanawut, F.W. Lim, Y.S. Bhole, D. Ormerod, A. Horvath, A.T. Boam, A.G. Livingston, Demonstration of Molecular Purification in Polar Aprotic Solvents by Organic Solvent Nanofiltration, Organic Process Research \& Development, 14 (2010) 600-611.

[9] J.F. Kim, G. Szekely, M. Schaepertoens, I.B. Valtcheva, M.F. Jimenez-Solomon, A.G. Livingston, In Situ Solvent Recovery by Organic Solvent Nanofiltration, ACS Sustainable Chemistry \& Engineering, 2 (2014) 2371-2379.

[10] D. Ormerod, B. Noten, M. Dorbec, L. Andersson, A. Buekenhoudt, L. Goetelen, Cyclic Peptide Formation in Reduced Solvent Volumes via In-Line Solvent Recycling by Organic Solvent Nanofiltration, Organic Process Research \& Development, (2015).

[11] E.M. Rundquist, C.J. Pink, A.G. Livingston, Organic solvent nanofiltration: a potential alternative to distillation for solvent recovery from crystallisation mother liquors, Green Chemistry, 14 (2012) 2197-2205.

[12] J.F. Kim, A.M. Freitas da Silva, I.B. Valtcheva, A.G. Livingston, When the membrane is not enough: A simplified membrane cascade using Organic Solvent Nanofiltration (OSN), Separation and Purification Technology, 116 (2013) 277-286.

[13] L.S. White, A.R. Nitsch, Solvent recovery from lube oil filtrates with a polyimide membrane, Journal of Membrane Science, 179 (2000) 267-274.

[14] M. Priske, M. Lazar, C. Schnitzer, G. Baumgarten, Recent Applications of Organic Solvent Nanofiltration, Chemie Ingenieur Technik, 88 (2016) 39-49.

[15] R. Abejón, A. Garea, A. Irabien, Analysis and optimization of continuous organic solvent nanofiltration by membrane cascade for pharmaceutical separation, AIChE Journal, 60 (2014) 931948.

[16] N.V. Patil, A.E.M. Janssen, R.M. Boom, The potential impact of membrane cascading on downstream processing of oligosaccharides, Chemical Engineering Science, 106 (2014) 86-98. [17] F.P. McCandless, A comparison of membrane cascades, some one-compressor recycle permeators, and distillation, Journal of Membrane Science, 89 (1994) 51-72.

[18] J. Vanneste, D. Ormerod, G. Theys, D. Van Gool, B. Van Camp, S. Darvishmanesh, B. Van der Bruggen, Towards high resolution membrane-based pharmaceutical separations, Journal of Chemical Technology \& Biotechnology, 88 (2013) 98-108.

[19] A. Caus, L. Braeken, K. Boussu, B. Van der Bruggen, The use of integrated countercurrent nanofiltration cascades for advanced separations, Journal of Chemical Technology \& Biotechnology, 84 (2009) 391-398. 


\section{ACCEPTED MANUSCRIPT}

[20] A. Caus, S. Vanderhaegen, L. Braeken, B. Van der Bruggen, Integrated nanofiltration cascades with low salt rejection for complete removal of pesticides in drinking water production, Desalination, 241 (2009) 111-117.

[21] A. Cano-Odena, P. Vandezande, D. Fournier, W. Van Camp, F.E. Du Prez, I.F.J. Vankelecom, Solvent-Resistant Nanofiltration for Product Purification and Catalyst Recovery in Click Chemistry Reactions, Chemistry - A European Journal, 16 (2010) 1061-1067.

[22] W.E. Siew, A.G. Livingston, C. Ates, A. Merschaert, Continuous solute fractionation with membrane cascades - A high productivity alternative to diafiltration, Separation and Purification Technology, 102 (2013) 1-14.

[23] A.R.S. Teixeira, J.L.C. Santos, J.G. Crespo, Solvent resistant diananofiltration for production of steryl esters enriched extracts, Separation and Purification Technology, 135 (2014) 243-251.

[24] N.V. Patil, X. Feng, J.J.W. Sewalt, R.M. Boom, A.E.M. Janssen, Separation of an inulin mixture using cascaded nanofiltration, Separation and Purification Technology, 146 (2015) 261-267.

[25] N.V. Patil, T. Schotel, C.V. Rodríguez Gómez, V. Aguirre Montesdeoca, J.J.W. Sewalt, A.E.M. Janssen, R.M. Boom, Continuous purification of galacto-oligosaccharide mixtures by using cascaded membrane filtration, Journal of Chemical Technology \& Biotechnology, (2015) n/a-n/a.

[26] J.C.-T. Lin, A.G. Livingston, Nanofiltration membrane cascade for continuous solvent exchange, Chemical Engineering Science, 62 (2007) 2728-2736.

[27] W.E. Siew, A.G. Livingston, C. Ates, A. Merschaert, Molecular separation with an organic solvent nanofiltration cascade - augmenting membrane selectivity with process engineering, Chemical Engineering Science, 90 (2013) 299-310.

[28] N.A. Luechinger, W.J. Stark, C.R. Kellenberger, Pourous polymer membranes, in, ETH Zuerich, $\mathrm{CH}, 2011$.

[29] Novamem Ltd., Flatsheet membrane PEEK-PI, 10 x $10 \mathrm{~cm}, 4$ pieces, in, 2016.

[30] F. Davis, S. Higson, Macrocycles: Construction, Chemistry and Nanotechnology Applications, John Wiley \& Sons, Ltd., 2011.

[31] I.B. Valtcheva, S.C. Kumbharkar, J.F. Kim, Y. Bhole, A.G. Livingston, Beyond polyimide: Crosslinked polybenzimidazole membranes for organic solvent nanofiltration (OSN) in harsh environments, Journal of Membrane Science, 457 (2014) 62-72.

[32] I.B. Valtcheva, P. Marchetti, A.G. Livingston, Crosslinked polybenzimidazole membranes for organic solvent nanofiltration (OSN): Analysis of crosslinking reaction mechanism and effects of reaction parameters, Journal of Membrane Science, 493 (2015) 568-579.

\section{Highlights}

- Sustainable solvent recycle with nanofiltration membranes was demonstrated.

- Washing the solvent recovery stage circumvents limited impurity removal.

- Up to $96 \%$ less solvent consumption can be achieved.

- PI-PEEK membranes showed excellent performance in solvent recovery. 